Article

\title{
An Ab Initio Study of Connections between Tensorial Elastic Properties and Chemical Bonds in $\Sigma 5(210)$ Grain Boundaries in $\mathrm{Ni}_{3} \mathrm{Si}$
}

\author{
Martin Friák ${ }^{1, *}$, Martin Zelený ${ }^{2,3}$, Monika Všianská ${ }^{4,1,5}$, David Holec ${ }^{6}$ and Mojmír Šob ${ }^{5,1,4}$ \\ 1 Institute of Physics of Materials, Academy of Sciences of the Czech Republic, Žižkova 22, CZ-616 62 Brno, \\ Czech Republic; Monika.Vsianska@seznam.cz (M.V.); mojmir@ipm.cz (M.Š.) \\ 2 Institute of Materials Science and Engineering, NETME Centre, Faculty of Mechanical Engineering, \\ Brno University of Technology, Technická 2896/2, CZ-616 69 Brno, Czech Republic; zeleny@ipm.cz \\ 3 Faculty of Mathematics and Physics, Charles University in Prague, Ke Karlovu 5, \\ CZ-121 16 Prague, Czech Republic \\ 4 Central European Institute of Technology, CEITEC MU, Masaryk University, Kamenice 5, \\ CZ-625 00 Brno, Czech Republic \\ 5 Department of Chemistry, Faculty of Science, Masaryk University, Kotlářská 2, \\ CZ-611 37 Brno, Czech Republic \\ 6 Department of Physical Metallurgy and Materials Testing, Montanuniversität Leoben, Franz-Josef-Strasse 18, \\ A-8700 Leoben, Austria; david.holec@unileoben.ac.at \\ * Correspondence: friak@ipm.cz
}

Received: 16 October 2018; Accepted: 5 November 2018; Published: 13 November 2018

\begin{abstract}
Using quantum-mechanical methods we calculate and analyze (tensorial) anisotropic elastic properties of the ground-state configurations of interface states associated with $\Sigma 5(210)$ grain boundaries (GBs) in cubic $\mathrm{L}_{2}$-structure $\mathrm{Ni}_{3} \mathrm{Si}$. We assess the mechanical stability of interface states with two different chemical compositions at the studied GB by checking rigorous elasticity-based Born stability criteria. In particular, we show that a GB variant containing both $\mathrm{Ni}$ and $\mathrm{Si}$ atoms at the interface is unstable with respect to shear deformation (one of the elastic constants, $C_{55}$, is negative). This instability is found for a rectangular-parallelepiped supercell obtained when applying standard coincidence-lattice construction. Our elastic-constant analysis allowed us to identify a shear-deformation mode reducing the energy and, eventually, to obtain mechanically stable ground-state characterized by a shear-deformed parallelepiped supercell. Alternatively, we tested a stabilization of this GB interface state by $\mathrm{Al}$ substituents replacing Si atoms at the GB. We further discuss an atomistic origin of this instability in terms of the crystal orbital Hamilton population (COHP) and phonon dispersion calculations. We find that the unstable GB variant shows a very strong interaction between the $\mathrm{Si}$ atoms in the GB plane and Ni atoms in the 3rd plane off the GB interface. However, such bond reinforcement results in weakening of interaction between the $\mathrm{Ni}$ atoms in the 3rd plane and the $\mathrm{Si}$ atoms in the 5th plane making this GB variant mechanically unstable.
\end{abstract}

Keywords: $\mathrm{Ni}_{3} \mathrm{Si}$; grain boundaries; elasticity; ab initio; stability; phonon; $\mathrm{COHP}$

\section{Introduction}

Grain boundaries (GBs) represent one of the most important classes of extended defects. Their properties are crucial for many aspects of solid-state materials, including, e.g., their macroscopic strength [1-5]. GBs are becoming even more important due to the recent proliferation of technologies providing and utilizing ultra-fine grained or nano-granular materials. In these materials, the role 
of GB-affected regions may even dominate when compared with that of the grain interior itself. It also means that suitable design of GB-related states can also possibly lead to material systems with properties significantly different from the bulk [6-19]).

Properties of GBs are very sensitive to compositional changes [20-28], which can be, for example, driven thermodynamically. Impurities, even in very low concentrations (ppm), can drastically change GB characteristics (see, for example, Refs. [29,30]). One of the effects, which is usually associated with segregation of impurities on the GB, is intergranular embrittlement. It is accompanied by a profound reduction of the ductility and strength. Materials, which significantly suffer from intergranular fracture and low ductility, are $\mathrm{Ni}$-based $\mathrm{Ni}_{3} \mathrm{X}$ intermetallic compounds with the $\mathrm{L}_{2}$ crystal structure [31-33] although they exhibit a large potential for high temperature applications in corrosive atmospheres [34,35]. Their cohesive strengths at GB decrease with increasing valence difference between $\mathrm{Ni}$ and $\mathrm{X}$ atom and with increasing size of $\mathrm{X}$ atom in order $\mathrm{Ni}_{3} \mathrm{Al}>\mathrm{Ni}_{3} \mathrm{Ga}>\mathrm{Ni}_{3} \mathrm{Si}>\mathrm{Ni}_{3} \mathrm{Ge}[36,37]$. Another explanation derived from behavior of impurities in elemental metals [38] can be based on electronegativity of $X$ atom. The more electronegative atom $X$ at the GB is the higher the tendency for it to pull charge out of the $\mathrm{Ni}-\mathrm{Ni}$ bonds at the boundary, thereby reducing the cohesive strength and promoting intergranular fracture [37]. In case of $\mathrm{Ni}_{3} \mathrm{Al}$, this problem can be solved by adding a small amount of boron, which improves GB cohesion $[39,40]$ and changes intergranular character of fracture to transgranular. The same improvement of properties was, however, not observed after adding boron into $\mathrm{Ni}_{3} \mathrm{Si}$ intermetallic compound. Boron slightly increases ductility of $\mathrm{Ni}_{3} \mathrm{Si}$, while leaving the fracture mode unaffected [31,41]. On the other hand, GB properties can be strongly enhanced by adding a large amount of Ti resulting in a highly ordered $\mathrm{Ni}_{3}(\mathrm{Si}, \mathrm{Ti})$ alloy $[42,43]$.

The main goal of our present study is to determine and analyze tensorial, in particular elastic, properties of material regions affected by grain boundaries in $\mathrm{Ni}_{3} \mathrm{Si}$ and to connect interface-induced changes with properties of individual inter-atomic bonds. As far as tensorial elastic properties of GBs are concerned, we build upon the knowledge gained in our recent papers [44,45] which were focused on tensorial characteristics of $\Sigma 5(210)$ grain boundaries in $\mathrm{Ni}_{3} \mathrm{Al}$. These studies focused on two possible interface variants, which differ by local chemical composition. Both of them were found to have a significantly reduced shear elastic constant $\left(C_{55}\right)$ when compared with the bulk. This softening subsequently lowers a homogenized shear modulus and, using a classical approximative model of Slater [46], we predict that it may lead to lowering of the melting temperature [45]. Importantly, Si atoms added close to the GB interface plane of the elastically weaker variant were shown to radically alter the elastic properties and improve the softening. Similar softening leading to the complete mechanical instability of specific $\Sigma 5(210)$ GB in $\mathrm{Ni}_{3} \mathrm{Si}$ is thoroughly analyzed in the present study together with the stabilization effect of $\mathrm{Al}$ impurities. In order to do so, we compute and analyze phonon spectra, crystal orbital Hamilton population and densities of electronic states of the studied interface states.

\section{Methods}

Atomic configurations of GBs are often highly distorted and, therefore, it is truly advantageous to employ reliable theoretical tools, in particular quantum-mechanical (also called ab initio or first-principles) calculations, when studying them [47-55]. Our ab initio calculations are based on the density functional theory [56,57] and we used the Vienna Ab initio Simulation Package (VASP) [58,59] including the projector augmented-wave potentials [60]. The electronic wave functions were expanded in plane waves and the expansion was cut-off at those with the kinetic energy of $500 \mathrm{eV}$. Regarding the exchange and correlation energy, we employed the generalized gradient approximation as parametrized by Perdew, Burke, and Ernzerhof [61]. We used a $5 \times 17 \times 3$ Monkhorst-Pack k-point mesh for the 64 -atom supercells $\left(15 \times 15 \times 15\right.$ in the case of the 4-atom cell of $\mathrm{Ni}_{3} \mathrm{Si}$ bulk) and the Methfessel-Paxton smearing method [62] with a $0.1 \mathrm{eV}$ smearing width for integration over the Brillouin zone. To understand the inter-atomic interactions in the studied systems, the crystal orbital 
Hamilton population (COHP) and density of (electronic) states (DOS) analysis [63] based on projection of plane waves to a local basis [64] implemented in the program LOBSTER $2.1[65,66]$ were used.

For our study, we have chosen the $\Sigma 5(210)$ GB (see Figure 1) because it is, on one hand, rather symmetric but, on the other hand, it exhibits an additional volume (when compared with the bulk), similarly as it is the case in many non-special GBs. The two different GB chemical compositions corresponding to either solely $\mathrm{Ni}$ or both $\mathrm{Ni}$ and $\mathrm{Si}$ atoms at the GB plane are shown in Figure 1a,b, respectively. It is worth mentioning that the computational supercells are, in fact, periodic approximants of the real GB-associated interface states because the periodic boundary conditions are applied. Our study was aimed at determining thermodynamic, structural and tensorial elastic properties when all atomic positions as well as the shape and the volume of the supercell were fully relaxed reducing the forces on atoms under $1 \mathrm{meV} / \AA$. Finally, when simulating the application of external strains to determine the elastic constants (see Refs. [67,68]), we also relaxed the atomic positions. Our previous results for the same type of the $\mathrm{GB}$ in $\mathrm{Ni}_{3} \mathrm{Al}$ show that the most critical shear elastic constant, $C_{55}$, that could be as low as $15 \mathrm{GPa}$ in case when only $\mathrm{Ni}$ atoms are located at the interface of $\Sigma 5$ (210) in $\mathrm{Ni}_{3} \mathrm{Al}$, is much higher (64 GPa) if these atomic relaxations are omitted (see more details in our recent paper [44]).
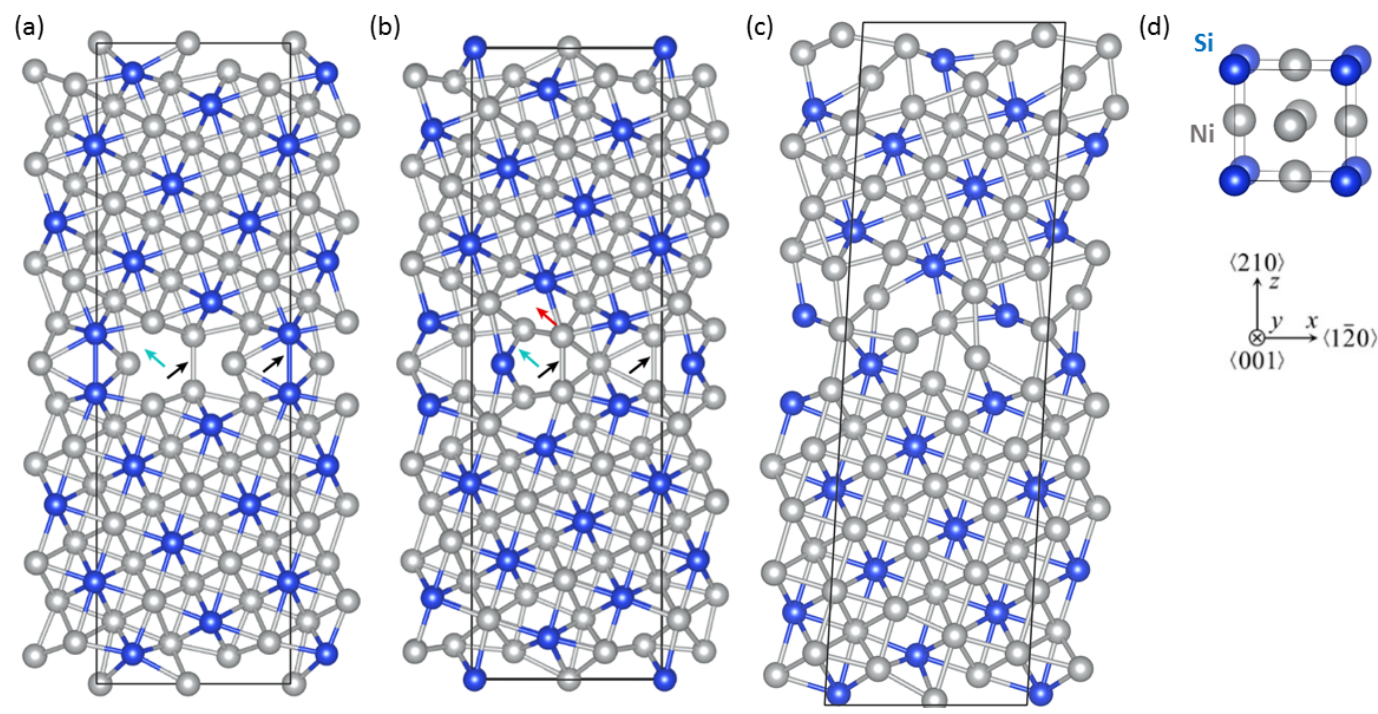

Figure 1. Visualization of computational supercells used in our calculations of interface states related to the $\Sigma 5(210)$ GBs in $\mathrm{Ni}_{3} \mathrm{Si}$ with different stoichiometries, (a) $\Sigma 5(210)^{\mathrm{Ni}, \mathrm{Ni}}$ with only $\mathrm{Ni}$ atoms at the GB plane, (b) $\Sigma 5(210)^{\mathrm{Si}, \mathrm{Ni}}$ with both $\mathrm{Si}$ and $\mathrm{Ni}$ atoms at the GB plane (mechanically unstable configuration characterized by a rectangular-parallelepiped supercell), (c) mechanically stable shear-deformed state of $\Sigma 5(210)^{\mathrm{Si}, \mathrm{Ni}}$ and (d) cubic $\mathrm{L1}_{2}$ unit cell of bulk $\mathrm{Ni}_{3} \mathrm{Si}$ together with crystallographic directions of GB supercell vectors (before the shear deformation). The Ni atoms are visualized as the blue spheres while the $\mathrm{Si}$ atoms as the gray ones. Arrows indicate specific inter-atomic bonds discussed in the text (see below). Please note that some atoms are shown together with their periodic images.

Lattice-dynamics calculations were performed with the Phonopy [69] package via the supercell finite-displacement method [70]. The second-order force-constants matrices were calculated using $2 \times 2 \times 1$ expansions of the 64-atom supercell describing GBs with a displacement step size of $10^{-2} \AA$. The $3 \times 3 \times 3$ expansion of $\mathrm{L1}_{2}$ unit cell was used for the bulk $\mathrm{Ni}_{3} \mathrm{Si}$. We found that these cells were sufficiently large to converge the shape of the density of phonon states (DPS). Calculated force-constant matrices were subsequently projected on the unit vector along each bonding direction to obtain information about bond "stiffness" [71]. The DPS curves were constructed by evaluating the phonon frequencies on $25 \times 45 \times 15$ and $20 \times 20 \times 20$ Monkhorst-Pack q-point grid for GBs and the bulk, respectively. 


\section{Results}

Our quantum-mechanical calculations of the bulk $\mathrm{Ni}_{3} \mathrm{Si}$ with the $\mathrm{L}_{2}$ structure predict its lattice parameter to be $3.511 \AA$ in perfect agreement with the experimental value of $3.5002 \AA$ [72]. Regarding $\Sigma 5(210) \mathrm{GBs}$ in $\mathrm{Ni}_{3} \mathrm{Si}$, the computed GB energies are very similar for both compositional variants, 1.49 and $1.59 \mathrm{~J} / \mathrm{m}^{2}$ for the $\Sigma 5(210)^{\mathrm{Ni}, \mathrm{Ni}}$ with only $\mathrm{Ni}$ atoms at the interface (Figure 1a) and $\Sigma 5(210)^{\mathrm{Si}, \mathrm{Ni}}$ with both types of atoms ( $\mathrm{Si}$ and $\mathrm{Ni}$ ) at the interface (Figure $1 \mathrm{~b}$ ), respectively. The studied GBs have also different volumes when compared with the bulk $\mathrm{Ni}_{3} \mathrm{Si}$ (see also the lattice parameters in Table 1). This additional volume is an averaged value when the additional volume obtained for the whole computational cell is divided by the total area of the two GBs inside of the supercell (it is thus expressed as a length parameter). Its value is nearly identical for both GB variants, 0.3195 and $0.3189 \AA$ (i.e., $\AA^{3} / \AA^{2}$ ) in the case of the $\Sigma 5(210)^{\mathrm{Ni}, \mathrm{Ni}}$ and $\Sigma 5(210)^{\mathrm{Si}, \mathrm{Ni}}$, respectively. It should be noted that alternative ways of analyzing the additional volume exist in literature (see, e.g., vertical atomic-layer-resolved shifts that are analyzed in the recent study by Kumar et al. [73]).

Table 1. The calculated lattice parameters within the (210) interface plane of the studied GBs. The values are compared with those obtained for the bulk for the same plane. The lattice parameters along the $\langle 120\rangle$ direction, $x$, and $\langle 001\rangle$ direction, $y$ (see Figure 1) are included together with their changes (expressed relatively in \% with respect to the bulk).

\begin{tabular}{|c|c|c|c|c|c|}
\hline & \multirow{2}{*}{$\begin{array}{c}\text { Bulk } \\
\text { (̊̊) }\end{array}$} & \multicolumn{2}{|c|}{$\Sigma 5(210)^{\mathrm{Si}, \mathrm{Ni}}$} & \multicolumn{2}{|c|}{$\Sigma 5(210)^{\mathrm{Ni}, \mathrm{Ni}}$} \\
\hline & & (̊̊) & $(\%)$ & (Å) & $(\%)$ \\
\hline & 7853 & 7.73 & -1 & 7.808 & -0.56 \\
\hline$y\langle 001\rangle$ & 3.512 & 3.523 & 0.31 & 3.515 & 0.09 \\
\hline
\end{tabular}

Next, we determine the elastic properties. The three elastic constants in the case of the cubic $\mathrm{Ni}_{3} \mathrm{Si}$ at $T=0 \mathrm{~K}$ amount to $C_{11}=312 \mathrm{GPa}, C_{12}=163 \mathrm{GPa}$ and $C_{44}=130 \mathrm{GPa}$. They are in reasonable agreement with rather broad range of experimental values ( $C_{11}$ is reported to be from $265 \mathrm{GPa}$ [74] to $370 \mathrm{GPa}$ [75], $C_{12}$ from $170 \mathrm{GPa}$ [74] to $212 \mathrm{GPa}$ [76] and $C_{44}$ ranges from $125 \mathrm{GPa}$ [74] to $224 \mathrm{GPa}$ [76]) as well as theoretical values of $C_{11}=269 \mathrm{GPa}, C_{12}=140 \mathrm{GPa}$ and $C_{44}=108 \mathrm{GPa}$ from Ref. [77].

Calculated elastic constants of all studied GB systems are given in Tables 2 and A1 in the Appendix A together with bulk elastic constants in the same coordination system. In addition to providing numerical values of individual elastic constants, we also visualize these elastic properties.

Table 2. The computed elastic constants (all in GPa) of (i) the $\mathrm{Ni}_{3} \mathrm{Si}$ bulk in the coordination system of the studied GBs (shown in Figure 1), (ii) two types of $\mathrm{Ni}_{3} \mathrm{Si} \Sigma 5(210)$ GBs with different atoms (see Figure 1) at the interface and (iii) systems with $\mathrm{Al}$ atom substituting $\mathrm{Si}$ atom within the GB interface plane $\mathrm{Ni}_{3}\left(\mathrm{Si}, \mathrm{Al}_{\mathrm{Si}}\right) \Sigma 5(210)^{\mathrm{Si}, \mathrm{Ni}}$. In the case of $\Sigma 5(210)^{\mathrm{Si}, \mathrm{Ni}}$ we list elastic constants for the rectangular-parallelepiped supercells (these systems are mechanically not stable) as well as the shear-deformed ones (these are mechanically stable).

\begin{tabular}{lccccccccc}
\hline $\mathrm{Ni}_{3}$ Si States: & $C_{\mathbf{1 1}}$ & $C_{\mathbf{1 2}}$ & $C_{\mathbf{1 3}}$ & $C_{\mathbf{2 2}}$ & $C_{\mathbf{2 3}}$ & $C_{\mathbf{3 3}}$ & $C_{\mathbf{4 4}}$ & $C_{55}$ & $C_{\mathbf{6 6}}$ \\
\hline bulk $\langle 1 \overline{2} 0\rangle\langle 001\rangle\langle 210\rangle$ & 346 & 164 & 128 & 310 & 164 & 348 & 130 & 94 & 130 \\
$\Sigma 5(210)^{\mathrm{Ni}, \mathrm{Ni}}$ & 301 & 155 & 135 & 274 & 165 & 276 & 96 & 12 & 115 \\
$\Sigma 5(210)^{\mathrm{Si}, \mathrm{Ni}}$ rectangular & 277 & 163 & 151 & 265 & 168 & 259 & 51 & -98 & 108 \\
$\Sigma 5(210)^{\mathrm{Si}, \mathrm{Ni}}$ sheared & 387 & 166 & 136 & 264 & 162 & 285 & 79 & 37 & 114 \\
\hline $\mathrm{Al}_{\mathrm{Si}} \Sigma 5(210)^{\mathrm{Si}, \mathrm{Ni}}$ & 282 & 172 & 131 & 256 & 152 & 283 & 61 & 30 & 115 \\
\hline
\end{tabular}

In particular we show how the studied GB interface states respond to uniaxial loading along different crystallographic directions by exhibiting directional dependences of the Young's modulus in Figures 2 and 3. Tensorial elastic properties provide the wealth of insight and understanding. 
For example, they allow us to rigorously assess the mechanical stability of the studied system (employing so-called Born stability criteria [78,79]).

(a)

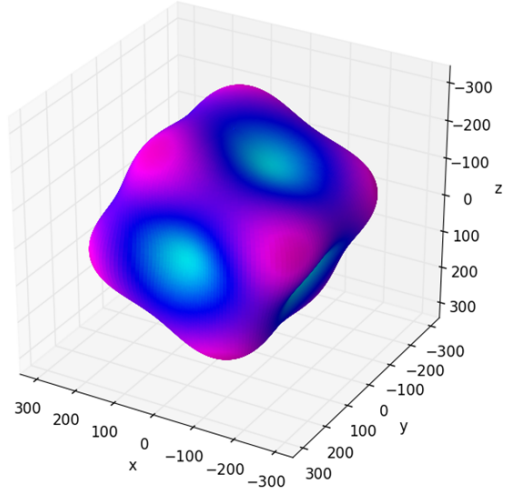

(c)

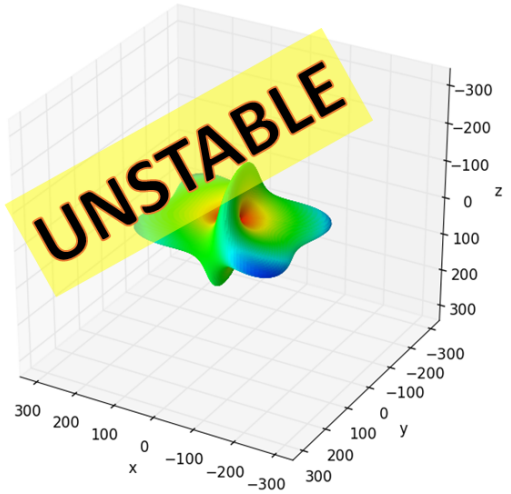

(b)
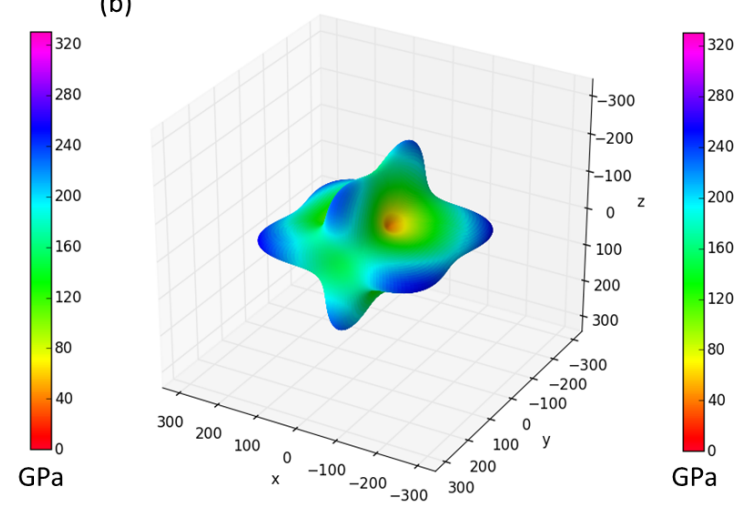

(d)

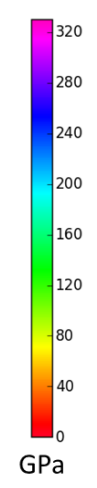

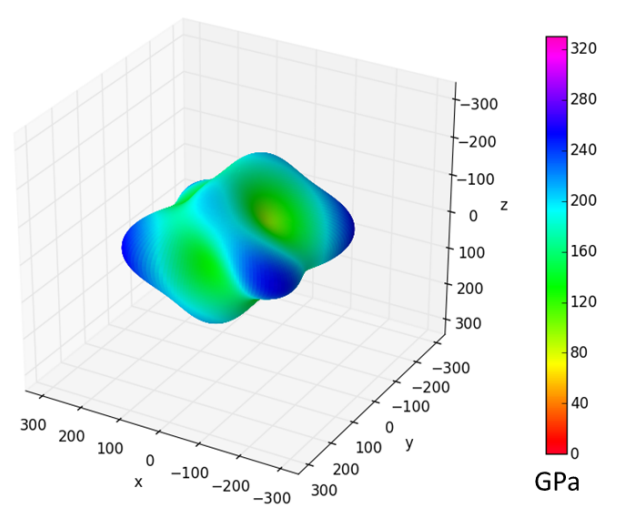

Figure 2. Visualization of directional dependences of the Young's modulus of the studied $\mathrm{Ni}_{3} \mathrm{Si}_{\mathrm{i}} \mathrm{systems,}$ (a) the $\mathrm{Ni}_{3} \mathrm{Si}$ bulk in the coordination system of the studied GBs, (b) $\Sigma 5(210)^{\mathrm{Ni}, \mathrm{Ni}}$, (c) mechanically unstable $\Sigma 5(210)^{\mathrm{Si}, \mathrm{Ni}}$ (rectangular-parallelepiped supercell) and (d) mechanically stable $\Sigma 5(210)^{\mathrm{Si}, \mathrm{Ni}}$ (sheared-parallelepiped supercell) when the GBs plane is the $x-y$ plane. The directional dependences were visualized by the SC-EMA [80-82] library (scema.mpie.de) and derived from the elastic constants (Tables 2 and A1 in the Appendix A).

When inspecting Figures 2 and 3, it is obvious that the GB-related interface states $\Sigma 5(210)^{\mathrm{Ni}, \mathrm{Ni}}$ (Figure $2 \mathrm{~b}$ ) and $\Sigma 5(210)^{\mathrm{Si}, \mathrm{Ni}}$ (Figure $2 \mathrm{~d}$ ) exhibit lower maximum values of the Young's modulus, lower (by $\approx 100 \mathrm{GPa}$ ) than the bulk $\mathrm{Ni}_{3} \mathrm{Si}$ (Figure 2a). The interface states are thus softer than the bulk. Checking the underlying elastic constants in Table 2 in the case of the $\Sigma 5(210)^{\mathrm{Ni}, \mathrm{Ni}}$ compositional variant we see that nearly all elastic constants are lower than those of bulk $\mathrm{Ni}_{3} \mathrm{Si}$. The most dramatic reduction is related to $C_{55}$ elastic constant which is equal only to $12 \mathrm{GPa}$. This is nearly 8 times lower value than in the bulk $\left(C_{55}=94 \mathrm{GPa}\right)$. Here, we recall Born stability criteria (see, e.g., [78]) that connect the mechanical stability of a studied system with the positiveness of leading principal minors of the matrix of its elastic constants. The diagonal elements $C_{44}, C_{55}$ and $C_{66}$ must be positive and the above-discussed drop predicted for $C_{55}$ thus identifies the weakest link. Also, the elastic anisotropy is significantly enhanced when compared with the bulk. Using the ELATE software [83] the stiffest directions is identified to have the Young's modulus equal to $257 \mathrm{GPa}$ (color-coded dark blue in Figure $2 b$ ), i.e., within the same crystallographic plane as the GB interface, while the softest direction with the Young's modulus is approaching only $42 \mathrm{GPa}$ (red colors in Figure 2b) and is inclined to the GB interface plane. 


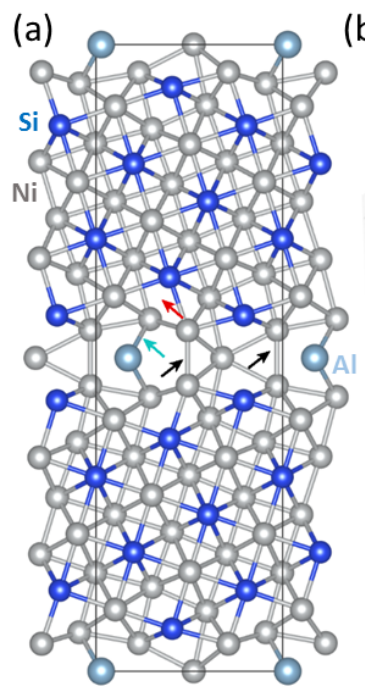

(b)

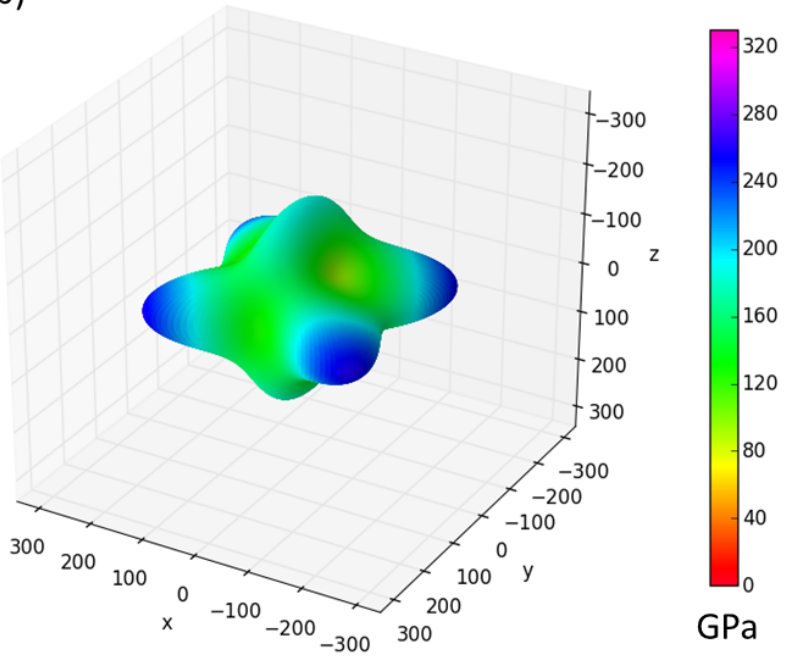

Figure 3. (a) Schematic visualization of the supercell of the $\Sigma 5(210)^{\mathrm{Si}, \mathrm{Ni}}$ interface state with $\mathrm{Si}$ atoms at the interface plane substituted by $\mathrm{Al}$ atoms and (b) corresponding directional dependences of the Young's modulus. The latter was computed and visualized by the SC-EMA [80-82] library (scema.mpie.de) based on quantum-mechanically computed elastic constants (Tables 2 and A1 in the Appendix A). Arrows indicate specific inter-atomic bonds discussed in the text (see below).

The $C_{55}$ elastic constant related to shear deformations has turned out to be crucial for the stability of the studied GB states. In particular, the higher-energy $\Sigma 5(210)^{\mathrm{Si}, \mathrm{Ni}} \mathrm{GB}$ described by the original rectangular-parallelepiped atomic configuration (see Figure $1 \mathrm{~b}$ ) is predicted to have the $C_{55}$ elastic constant negative (equal to $-98 \mathrm{GPa}$, directional dependence in Figure $2 \mathrm{c}$ is obtained when artificially setting the value of $C_{55}$ to $10 \mathrm{GPa}$ ). As this violates the Born stability criteria, this configuration is mechanically unstable. Importantly, our calculations of elastic constants have not only identified the original atomic configuration of $\Sigma 5(210)^{\mathrm{Si}, \mathrm{Ni}} \mathrm{GB}$ as mechanically unstable but also allowed us to track the deformation mode, which leads to lowering of the energy when compared to the undeformed state, and find the mechanically stable lowest-energy configuration. It is a sheared atomic configuration (see Figure 1c) and its elastic constants are given in Tables 2 and A1 mentioned in the Appendix A). In particular, the value of $C_{55}$ is predicted to be $37 \mathrm{GPa}$. This is nevertheless still nearly three times lower than the corresponding bulk value. The Young's modulus for this configuration is depicted in Figure 2d.

The above-discussed lower value of the shear elastic constant $C_{55}$ is also, in fact, in qualitative agreement with previous findings $[84,85]$ reported for GBs in elemental face-centered cubic (fcc) metals. In these studies, atomistic simulations were combined with a method that allows to decompose an overall elasticity into that of different atomic layers and, similarly as in our study, the shear elastic constants were found reduced close to the GB plane [85].

The overall comparison of the above-discussed cases of $\Sigma 5(210)^{\mathrm{Ni}, \mathrm{Ni}}$ and $\Sigma 5(210)^{\mathrm{Si}, \mathrm{Ni}}$ GB interface states neatly illustrates a very high sensitivity of anisotropic (tensorial) elastic properties of these states to compositional changes at the interface plane. Therefore, we have made a step in the direction of a materials design of GB states and also tried to stabilize the original atomic configuration of $\Sigma 5(210)^{\mathrm{Si}, \mathrm{Ni}}$ GB by substituting the interface Si atom by Al (see atoms in Figure 3a) as a less electronegative element. This substituted state is indeed stable as far as the elastic constants are concerned $\left(C_{55}=\right.$ $30 \mathrm{GPa}$ ). The corresponding elastic constants are listed in Tables 2 and A1 (in the Appendix A) and the directional dependence of the Young's modulus is exhibited in Figure $3 b$.

\section{Discussion}

For deeper understanding of mechanical and thermodynamic instability of $\Sigma 5(210)^{\mathrm{Si}, \mathrm{Ni}} \mathrm{GB}$ and stabilization effect of $\mathrm{Al}$, we further analyze vibrational properties represented by phonons and 
chemical bonding embodied in electronic structure of studied periodic approximants of GBs. Lattice instabilities could be usually associated with increasing of DOS at the Fermi level, $E_{\mathrm{F}}$. Total DOS of all studied GBs are very similar to DOS of bulk $\mathrm{Ni}_{3} \mathrm{Si}$ (see Figure 4a). Small deviations can be found around the $E_{\mathrm{F}}$ (see the inset in Figure $4 \mathrm{a}$ ). The $\Sigma 5(210)^{\mathrm{Si}, \mathrm{Ni}} \mathrm{GB}$ shows significantly higher DOS at the $E_{\mathrm{F}}$ than $\Sigma 5(210)^{\mathrm{Ni}, \mathrm{Ni}} \mathrm{GB}$ which indicates its lower stability. Decrease of DOS at the $E_{\mathrm{F}}$ can be reached by shearing of $\Sigma 5(210)^{\mathrm{Si}, \mathrm{Ni}} \mathrm{GB}$ resulting in its stabilization, whereas substitution of $\mathrm{Al}$ atoms at the GB leaves DOS almost unchanged.
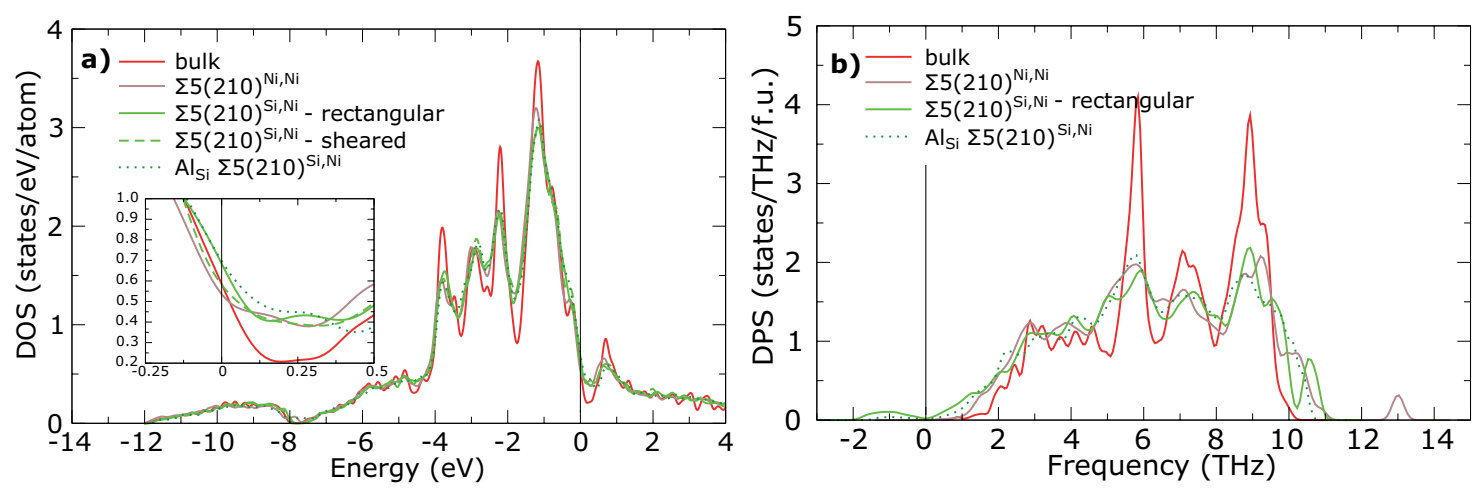

Figure 4. (a) Total density of states (DOS) per atom for all studied GBs and bulk $\mathrm{Ni}_{3} \mathrm{Si}$. The inset figure shows the DOS around the Fermi level, $E_{\mathrm{F}}$, which is set to be the energy zero. (b) Total density of phonon states (DPS) per formula unit for all undistorted GBs and bulk $\mathrm{Ni}_{3} \mathrm{Si}$ (see also the phonon spectra in the Appendix A).

Stability of GB can be better judged by inspecting the density of phonon states (DPS) in Figure $4 \mathrm{~b}$. The $\Sigma 5(210)^{\mathrm{Si}, \mathrm{Ni}} \mathrm{GB}$ exhibits significant soft modes with maxima of negative frequencies in phonon dispersion relation for $\mathbf{q}=(0,0.5,0)$ and $\mathbf{q}=(0.5,0.5,0.5)$, see Figure A1 in the Appendix. These soft modes are not presented in DPS curve of stable $\Sigma 5(210)^{\mathrm{Ni}, \mathrm{Ni}} \mathrm{GB}$, which, on the other hand, contains a high-frequency peak at $13 \mathrm{THz}$ corresponding to Si atoms in the 2nd layer of the GB interface. Imaginary part of DPS is significantly reduced for $\Sigma 5(210)^{\mathrm{Si}, \mathrm{Ni}} \mathrm{GB}$ with substituted $\mathrm{Al}$ atom (see Figure A1 in the Appendix). The soft mode at $\mathbf{q}=(0,0.5,0)$ disappears after substituting of Si by Al, but the soft mode at $\mathbf{q}=(0.5,0.5,0.5)$ still preserves. This indicates that $\Sigma 5(210)^{\mathrm{Si}, \mathrm{Ni}} \mathrm{GB}$ is not fully stabilized by Al.

To identify which particular atoms contribute to instability of GBs, we further plotted values of local DOS at the $E_{\mathrm{F}}$ as a function of $z$-coordinates in the supercell in Figure $5 \mathrm{a}$.
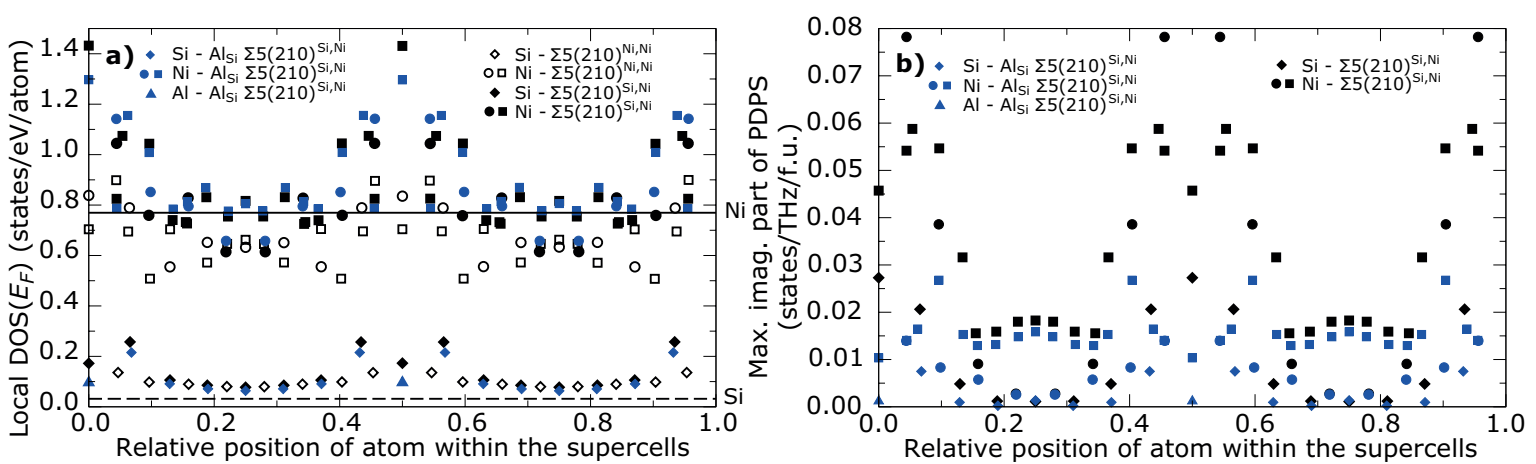

Figure 5. (a) Local density of states (DOS) at the Fermi level, $E_{\mathrm{F}}$, for each atom as a function $z$-coordinate in the supercell in all types of $\Sigma 5(210)$ GB. Horizontal lines represents local DOS at the $E_{\mathrm{F}}$ in bulk $\mathrm{Ni}_{3} \mathrm{Si}$. (b) The highest partial density of phonon states (PDPS) in imaginary frequencies for each atom as a function of $z$-coordinate in the supercell in both $\Sigma 5(210)^{\mathrm{Si}, \mathrm{Ni}} \mathrm{GB}$ with and without substituted $\mathrm{Al}$ atom. Squares represent $\mathrm{Ni}$ atoms in the layer occupied only by $\mathrm{Ni}$ atoms and circles represent $\mathrm{Ni}$ atoms in the layer occupied by $\mathrm{Ni}$ and $\mathrm{Si}$ atoms. 
Both $\Sigma 5(210)^{\mathrm{Si}, N i} \mathrm{~GB}$ with and without substituted $\mathrm{Al}$ atom exhibit increased DOS at $E_{\mathrm{F}}$ for atoms close to GB region when compared with the bulk $\mathrm{Ni}_{3} \mathrm{Si}$. The highest $\mathrm{DOS}$ at the $E_{\mathrm{F}}$ can be found for $\mathrm{Ni}$ atom exactly at the GB plane in $\Sigma 5(210)^{\mathrm{Si}, \mathrm{Ni}} \mathrm{GB}$ without $\mathrm{Al}$ atom. Substitution of $\mathrm{Al}$ atom results in a decrease of this value, which could indicate stabilization of GB. However, DOS at the $E_{\mathrm{F}}$ for $\mathrm{Ni}$ atoms in the 2nd layer slightly increases. The stable $\Sigma 5(210)^{\mathrm{Ni}, \mathrm{Ni}} \mathrm{GB}$ does not show this behavior and the DOS value at the $E_{\mathrm{F}}$ are very close to bulk values also for atoms at the GB region.

The significance of the stabilization effect of Al at GB may be seen from Figure $5 b$ where we plot the highest partial DPS for imaginary frequencies for both $\Sigma 5(210)^{\mathrm{Si}, \mathrm{Ni}} \mathrm{GB}$. The highest contribution to soft modes for $\mathrm{GB}$ without $\mathrm{Al}$ arise from $\mathrm{Ni}$ atoms in the 2nd layer. Also contributions of atoms in the 3rd and 4th layer are high. Surprisingly, Ni atom at GB does contribute so significantly and contribution of $\mathrm{Si}$ atom at GB is just slightly higher than contribution of other $\mathrm{Si}$ atoms in the supercell. Substitution of Si by Al significantly decreases imaginary phonon states for all atoms, with the strongest effect for atoms at the GB plane. The highest contribution to imaginary modes now can be found for atoms in the 4 th layer. This analysis of imaginary phonon states shows that instability of $\Sigma 5(210)^{\mathrm{Si}, N i} \mathrm{~GB}$ arises from atoms in the neighborhood of the GB plane than from atoms exactly at the GB plane.

To get a deeper insight into mutual chemical interaction between individual atoms we employed the analysis of crystal orbital Hamilton population (COHP) [63], which helps us to identify weaker chemical bonds in studied periodic approximants of GBs. Here a negative value of COHP represents bonding interaction in particular bands, whereas a positive COHP corresponds to antibonding interactions. Bands which do not participate in bonding between particular atoms do not appear in COHP curves. Thus, an integral of COHP up to Fermi level (ICOHP) represents the "chemical strength" of interaction between two atoms, where more negative value of ICOHP means a stronger interaction [86].

Another way how to judge the strength of a chemical bond from the point of view of lattice dynamics is a projection of the force constant obtained from phonon calculation on the unit vector along each bonding direction. It provides information about "bond stiffness" for a particular pair of atoms [71]. In the bulk $\mathrm{Ni}_{3} \mathrm{Si}$ (see Table 3), both nearest neighbor interactions exhibit almost the same ICOHP, but their bond-projected force constants, $\varphi_{\mathrm{B}}$, differ. The Ni-Ni bond seems to be much stronger than $\mathrm{Ni}-\mathrm{Si}$ bonds, which is in disagreement with previous analysis of bonds in $\mathrm{Ni}_{3} \mathrm{Si}$ based on charge-density plots $[87,88]$. Next-nearest neighbor interactions exhibit significantly smaller values of both quantities and probably have just a side effect on the stability of $\mathrm{Ni}_{3} \mathrm{Si}$ lattice.

Figure 6 shows the ICOHP values as a function of the projected force constant $\varphi_{\mathrm{B}}$ for all studied GBs. Several regions can be recognized in each trend. The weakest interactions between the next nearest neighbors are located in the upper-left corner of the each respective trend.

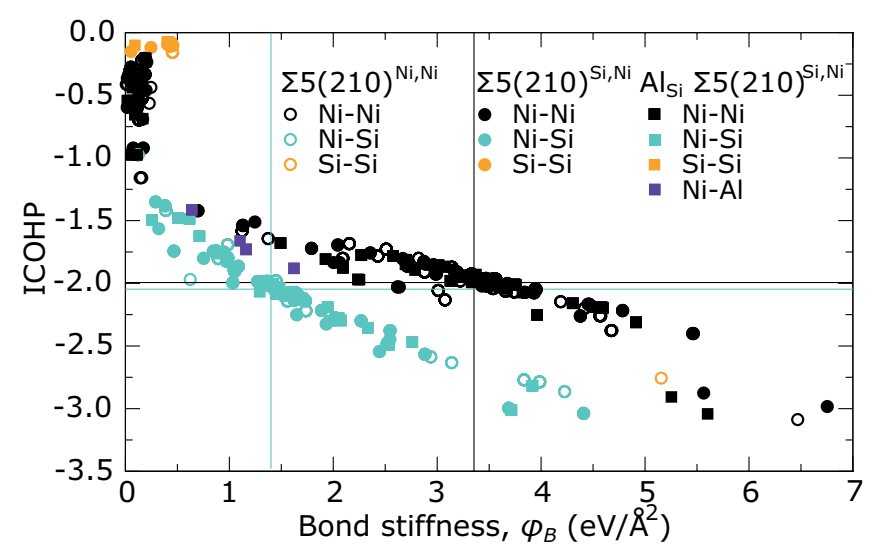

Figure 6. Integral of COHP up to the Fermi level as a function of projected force constant $\varphi_{\mathrm{B}}$ (bond stiffness) for $\Sigma 5(210)^{\mathrm{Ni}, \mathrm{Ni}} \mathrm{GB}$ (open circles), $\Sigma 5(210)^{\mathrm{Si}, \mathrm{Ni}} \mathrm{GB}$ (full circles) and $\Sigma 5(210)^{\mathrm{Si}, \mathrm{Ni}} \mathrm{GB}$ with Al (full squares). Black solid lines correspond to values for nearest neighbors $\mathrm{Ni}-\mathrm{Ni}$ bond in bulk $\mathrm{Ni}_{3} \mathrm{Si}_{\text {, }}$ whereas cyan solid lines represent Ni-Si bond. 
The strongest interaction can be found in the bottom-right corner, which corresponds to interactions across the GB plane between the atoms from the 2 nd layers. In case of $\Sigma 5(210)^{\mathrm{Si}, \mathrm{Ni}}$ GBs, there are two Ni-Ni interactions in the supercell, whereas the $\Sigma 5(210)^{\mathrm{Ni}, \mathrm{Ni}} \mathrm{GB}$ contains only a single $\mathrm{Ni}-\mathrm{Ni}$ interaction and a single $\mathrm{Si}-\mathrm{Si}$ interaction of this type. These interactions are marked by black arrows in Figure 1 as well as in Figure 7, which show ICOHP and $\varphi_{\mathrm{B}}$ as functions of bond length, respectively.

Table 3. Properties of nearest and next nearest neighbor bonds in bulk $\mathrm{Ni}_{3} \mathrm{Si}$ : bond length $d$, projected force constant $\varphi_{\mathrm{B}}$ and integral of COHP up to the Fermi level.

\begin{tabular}{lccc}
\hline & $\mathbf{d}(\AA)$ & $\varphi_{\mathbf{B}}\left(\mathbf{e V} / \AA^{2}\right)$ & ICOHP \\
\hline $\mathrm{Ni}-\mathrm{Ni}$ & 2.4828 & 3.35 & -2.08 \\
$\mathrm{Ni}-\mathrm{Si}$ & 2.4828 & 1.40 & -2.05 \\
$\mathrm{Si}-\mathrm{Si}$ & 3.5113 & 0.46 & -0.07 \\
$\mathrm{Ni}-\mathrm{Ni}$ (Ni-Si plane) & 3.5113 & 0.19 & -0.60 \\
$\mathrm{Ni}-\mathrm{Ni}$ (Ni plane) & 3.5113 & 0.03 & -0.41 \\
\hline
\end{tabular}
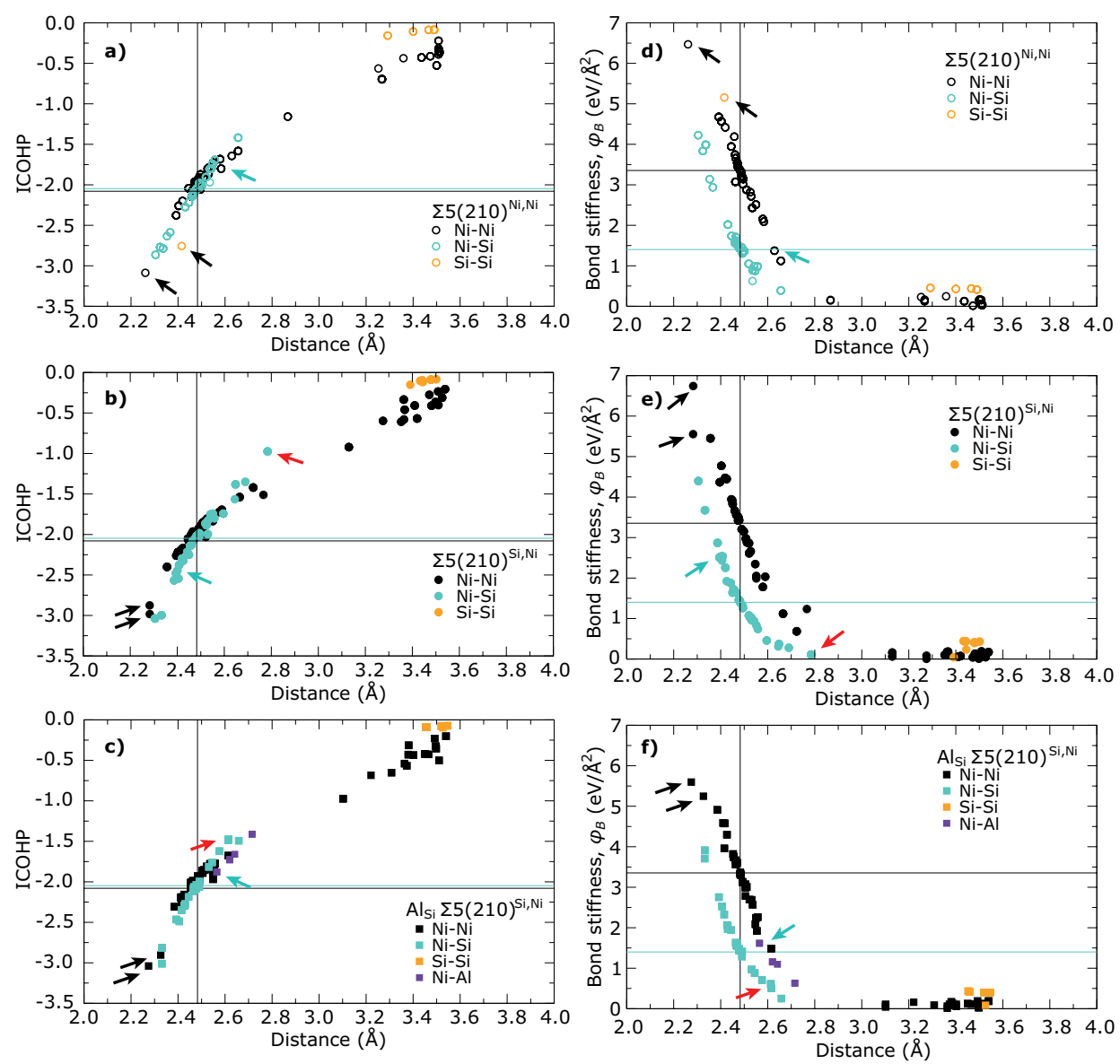

Figure 7. Left column: Integral of COHP up to the Fermi level as a function of the bond length for (a) $\Sigma 5(210)^{\mathrm{Ni}, N i} \mathrm{~GB},(\mathbf{b}) \Sigma 5(210)^{\mathrm{Si}, N i} \mathrm{~GB}$ and (c) $\Sigma 5(210)^{\mathrm{Si}, \mathrm{Ni}} \mathrm{GB}$ with Al. Black solid lines correspond to values for nearest neighbors $\mathrm{Ni}-\mathrm{Ni}$ bond in the bulk $\mathrm{Ni}_{3} \mathrm{Si}$, whereas cyan solid lines represent $\mathrm{Ni}-\mathrm{Si}$ bond. Right column: Projected force constant $\varphi_{\mathrm{B}}$ (bond stiffness) as a function of the bond length for (d) $\Sigma 5(210)^{\mathrm{Ni}, N i} \mathrm{~GB}$, (e) $\Sigma 5(210)^{\mathrm{Si}, \mathrm{Ni}} \mathrm{GB}$ and (f) $\Sigma 5(210)^{\mathrm{Si}, N i}$ GB with Al. Black solid lines correspond to values for nearest neighbors $\mathrm{Ni}-\mathrm{Ni}$ bond in bulk $\mathrm{Ni}_{3} \mathrm{Si}$, whereas cyan solid lines represent $\mathrm{Ni}-\mathrm{Si}$ bond. Arrows mark inter-atomic bonds discussed in text. 
Full COHP curves for these interactions are plotted in Figure 8a,b together with Ni-Ni interaction in the bulk $\mathrm{Ni}_{3} \mathrm{Si}$. Enhancement of $\mathrm{d}-\mathrm{d}$ bonding band around $3 \mathrm{eV}$ below the $E_{\mathrm{F}}$ is significant for all $\mathrm{Ni}-\mathrm{Ni}$ bonds across the GB compared with $\mathrm{Ni}-\mathrm{Ni}$ interaction in the bulk $\mathrm{Ni}_{3} \mathrm{Si}$. This enhancement is not affected by the substitution by the $\mathrm{Al}$ atoms. The Si-Si interaction in stable $\Sigma 5(210)^{\mathrm{Ni}, \mathrm{Ni}} \mathrm{GB}$ (orange open circles in Figures 6 and 7) seems to be weaker than Ni-Ni interaction (see Figure 8b). This conclusion is in line with the values of $C_{33}$ elastic constants in Table 2 which are lower for the studied GB states than in the bulk but still high enough to guarantee the mechanical stability.

Figure 6 further contains two almost linear dependencies for $\mathrm{Ni}-\mathrm{Ni}$ and $\mathrm{Ni}-\mathrm{Si}$ nearest neighbor interactions, which show that ICOHP is very well correlated with $\varphi_{\mathrm{B}}$ for a particular type of bond. As can be seen from Figure 7 the $\Sigma 5(210)^{\mathrm{Si}, \mathrm{Ni}} \mathrm{GB}$ contains also a large number of the Ni-Si bonds, which are significantly stronger than Ni-Si bonds in the bulk. The Ni-Al bonds in the substituted $\Sigma 5(210)^{\mathrm{Si}, \mathrm{Ni}} \mathrm{GB}$ (purple squares) exhibit a character more similar to $\mathrm{Ni}-\mathrm{Ni}$ bonds than to $\mathrm{Ni}-\mathrm{Si}$ bonds although $\mathrm{Al}$ replaces Si. To explain the instability of $\Sigma 5(210)^{\mathrm{Si}, \mathrm{Ni}} \mathrm{GB}$ we are looking for the weakest nearest neighbors interactions. It can be found between the Ni atoms in the 3rd layer and the Si atoms in the 5th layer (marked by red arrows in Figures 1 and 7) and shows also the longest inter-atomic distance out of all Ni-Si bonds, significantly longer than the Ni-Si bond in the bulk. Strengthening of this interaction as well as shortening of the bond length can be seen after replacing the Si atom at the GB plane by an $\mathrm{Al}$ atom. Although strengthening does not reach the level found in the case of the $\mathrm{Ni}-\mathrm{Si}$ interaction in bulk, it is sufficient to stabilize the GB. A comparing of COHP curves in Figure 8c shows that the character of interactions in both GBs is very similar to that in the bulk and it is just suppressed or enhanced due to a shorter or longer bond length.
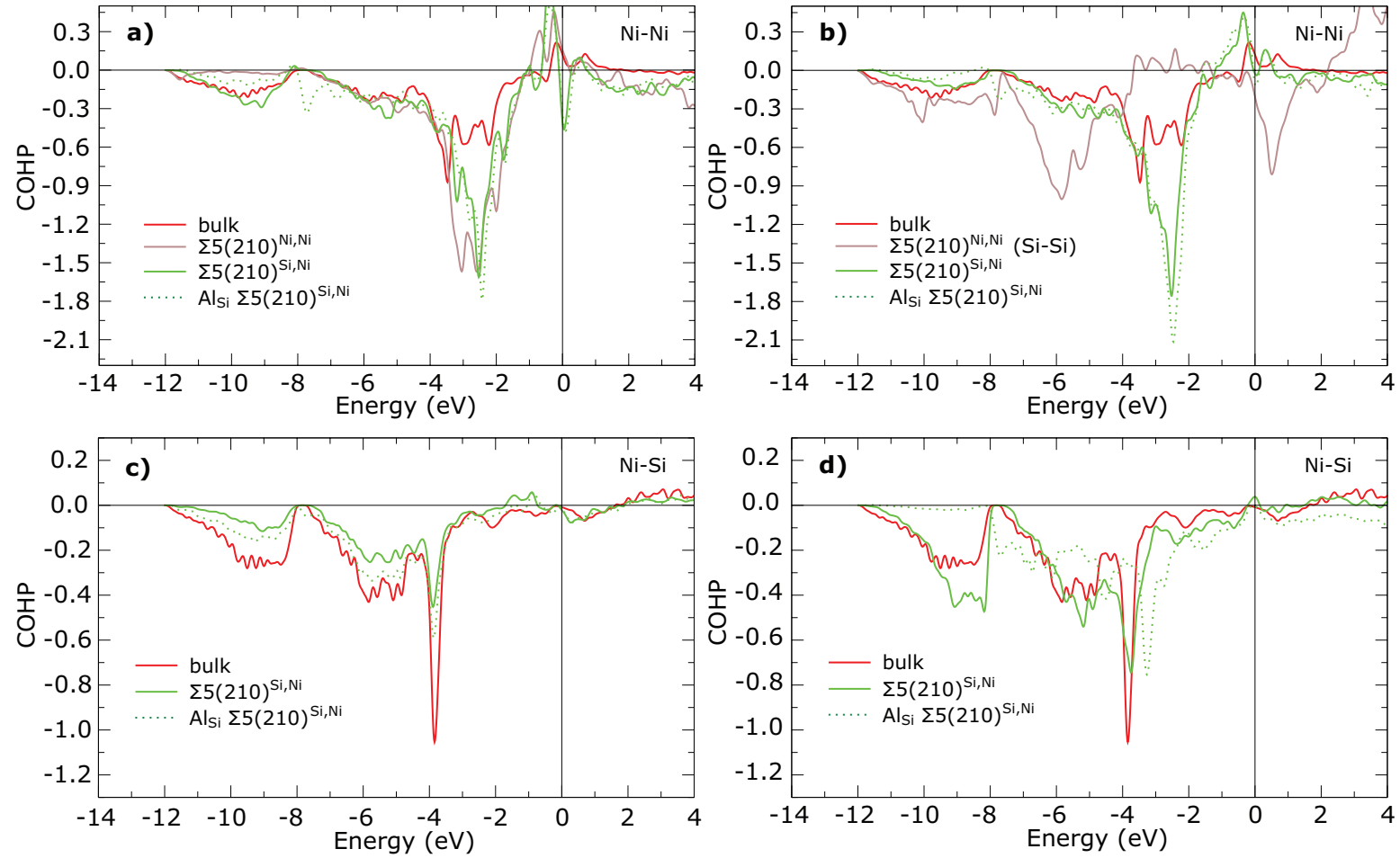

Figure 8. COHP curves for selected interatomic interactions in GBs and corresponding interactions in the bulk. (a) Interaction across the GB of Ni-Ni atoms from Ni plane between both 2nd layers (marked by a black arrow in other figures). (b) Interaction across the GB of Ni-Ni (Si-Si) atoms from NiSi plane between both 2 nd layers (marked by black arrows in other figures). (c) Interaction of Ni-Si atoms between the 3rd and 5 th layer (marked by red arrows in other figures). (d) Interaction of Ni-Si(Al) atoms between the GB and the 3rd layer (marked by cyan arrows in other figures).

To find the explanation for the weakening of this bond, we have to look closer at the GB plane. In particular, interaction between the Si atoms in the GB plane and the Ni atoms in the 3rd layer 
(marked by cyan arrows in Figures 1 and 7) belongs to that Ni-Si interaction with enhanced strength. As can be seen in Figure 8d, this enhancement arises from a strong s-s interaction at the bottom of valence bands. This very strong interaction, on the other hand, results in a weakening of the previously discussed $\mathrm{Ni}-\mathrm{Si}$ bond between the 3rd and the 5th layer. When the $\mathrm{Si}$ atom in the GB plane is replaced by the less electronegative $\mathrm{Al}$ atom, the corresponding $\mathrm{Ni}-\mathrm{Al}$ bond exhibits a significantly lower strength due to the missing s-s interaction. On the other hand this weak interaction allows a tighter $\mathrm{Ni}-\mathrm{Si}$ binding between the $3 \mathrm{rd}$ and the 5 th layers which stabilizes the $\Sigma 5(210)^{\mathrm{Si}, \mathrm{Ni}} \mathrm{GB}$. Thus, we can conclude that the $\Sigma 5(210)^{\mathrm{Si}, \mathrm{Ni}} \mathrm{GB}$ is not unstable due to a weak interaction between some atoms, but due to a strong interaction between the $\mathrm{Si}$ atoms in the GB plane and $\mathrm{Ni}$ atoms in the 3rd plane.

Stronger bonds between the $\mathrm{Si}$ atoms at the GB plane and Ni atoms in the 3rd layer can be also recognized from inter-layer distances shown in Figure 9. The value of the distance between the 2nd and 3rd layer (marked as "2/3" in Figure 9) is, in the case of atomic planes containing only Ni atoms in the $\Sigma 5(210)^{\mathrm{Si}, \mathrm{Ni}} \mathrm{GB}$, significantly shorter than all the other inter-planar distances between the 2nd and 3rd layers. Similarly, the distance between the 3rd and 4th layer in the same plane is significantly larger than all the other inter-planar distances between the 3rd and 4th layers. This indicates that the $\mathrm{Ni}$ atoms in the 3rd layer are strongly pulled towards the Si atoms at the GB plane. Inter-layer distances in Figure $9 \mathrm{~b}$ also show that the Ni atoms in the 3rd layer are pushed back to the position far from the GB plane, when the $\mathrm{Si}$ atom is replaced by the $\mathrm{Al}$ atom.
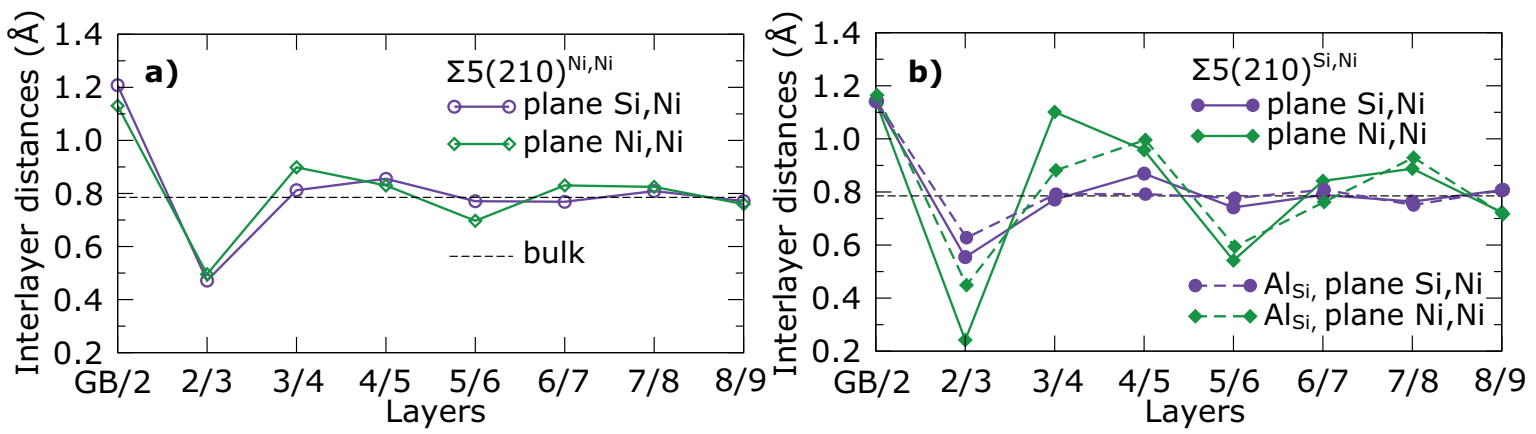

Figure 9. Ab initio computed distances between the (210) atomic planes in the supercells modeling (a) $\Sigma 5(210)^{\mathrm{Ni}, \mathrm{Ni}}$ and (b) $\Sigma 5(210)^{\mathrm{Si}, \mathrm{Ni}}$ interface states without (solid line) and with (dashed line) substituted $\mathrm{Al}$ atom at GB compared with the value calculated for the bulk.

\section{Conclusions}

We have performed an ab initio study of tensorial elastic properties of the interface states in $\mathrm{Ni}_{3} \mathrm{Si}$ associated with the $\Sigma 5(210)$ grain boundary. Rather complex tensorial elasto-chemical aspects of the studied periodic GB approximants were shown in the case of states with different atoms at the GB plane (either only Ni atoms $\left(\Sigma 5(210)^{\mathrm{Ni}, \mathrm{Ni}}\right.$ ) or both $\mathrm{Si}$ and $\mathrm{Ni}$ atoms $\left(\Sigma 5(210)^{\mathrm{Si}, \mathrm{Ni}}\right)$ ). The $\Sigma 5(210)^{\mathrm{Ni}, \mathrm{Ni}}$ GB state is predicted to have only a slightly lower interface energy of the two studied variants. The elastic constants are found to depend very sensitively on the GB plane chemical composition. In particular, the GB variant containing both $\mathrm{Ni}$ and $\mathrm{Si}$ atoms at the interface is shown to be unstable with respect to a shear deformation (one of the elastic constants, $C_{55}$, is negative). This instability is found for a rectangular-parallelepiped supercell obtained when applying a standard coincidence-lattice construction. Our elastic-constant analysis allowed us to identify a shear-deformation mode reducing the energy and eventually to obtain a mechanically stable ground-state characterized by a shear-deformed parallelepiped supercell. Nevertheless, a three-/eight-fold reduction of the elastic constant $C_{55}$ (when compared with the bulk value) is identified as the crucial weakest link for the mechanical stability for the studied GB states. We have also partly stabilized this GB interface state by $\mathrm{Al}$ substituent replacing $\mathrm{Si}$ atoms at the GB.

Next, an origin of this elastic softening and instability of the rectangular-parallelepiped $\Sigma 5(210)^{\mathrm{Si}, \mathrm{Ni}} \mathrm{GB}$ variant is discussed in terms chemical inter-atomic interactions described by the 
crystal orbital Hamilton population (COHP). Lattice-dynamics properties represented by projected force-constant matrices on the unit vector along each bonding direction were considered as well. Such complex analysis reveals a weak interaction far from the GB interface between the Ni atoms in the 3 rd plane and the Si atoms in the 5th plane. However, this bond weakening is a consequence of a very strong interaction between the $\mathrm{Si}$ atoms in the GB plane and $\mathrm{Ni}$ atoms in the 3rd plane off the GB interface. The same strong interaction was not observed when Si atom at the GB is replaced by Al. Thus the strong interaction near the GB plane makes this GB variant mechanically unstable.

Our study thus demonstrates very clearly shows the importance of anisotropic elastic-constant analysis for next studies of interface states close to GBs when determining their mechanical (in-)stability. Our analysis represents a complement to numerous previous studies of GBs which were focused predominantly on scalar characteristics (i.e., energy, strength, changes in inter-atomic bonds, as well as electronic structure and atomic configuration, see e.g., Refs. [4,20,89-101]). Our small-deformation anisotropic-elasticity assessment should be ideally extended in future by simulations of larger deformations [102-105] which have been rather rarely studied so far in case of GBs (see, e.g., Ref. [106]). The found sensitivity of the elasto-chemical inter-relations, which was additionally exemplified by studying the impact caused by $\mathrm{Al}$ atoms substituting $\mathrm{Si}$ atoms at the GB interface plane, paves a new approach towards a solute-controlled design of interface states with on-demand tensorial elastic properties and stability.

Author Contributions: Conceptualization, M.F. and M.Z.; Methodology, M.Z., D.H. and M.V.; Resources, M.Š.; Writing-Original Draft Preparation, M.F. and M.Z.; Writing-Review \& Editing, D.H., M.V. and M.Š.; Visualization, M.F., M.V. and M.Z.; Supervision, Project Administration and Funding Acquisition, M.Š.

Funding: The authors acknowledge the Czech Science Foundation for the financial support received under the Project No. 16-24711S (M.F., M.V., M.̌̌.). Additional resources were provided by the Academy of Sciences of the Czech Republic through the Fellowship of J. E. Purkyně (M.F.), by the Ministry of Education, Youth and Sports of the Czech Republic under the Project CEITEC 2020, LQ1601 (M.Š., M.V.) and by the ESIF, EU Operational Programme Research, Development and Education within the research project "Architectured materials designed for additive manufacturing", Reg. No.: CZ.02.1.01/0.0/0.0/16_025/0007304 (M.Z.).

Acknowledgments: M.F., M.V. and M.Š. also acknowledge the support from the Academy of Sciences of the Czech Republic (Institutional Project No. RVO:68081723) and from the Ministry of Education, Youth and Sports of the Czech Republic via the research infrastructure IPMINFRA, LM2015069. Computational resources were made available by the Ministry of Education, Youth and Sports of the Czech Republic under the Projects CESNET (Project No. LM2015042), CERIT-Scientific Cloud (Project No. LM2015085) and IT4Innovations National Supercomputer Center (Project No. LM2015070) within the program Projects of Large Research, Development and Innovations Infrastructures. Figures 1a-c and 3a were visualized using the VESTA package [107].

Conflicts of Interest: The authors declare no conflict of interest.

\section{Appendix A}

Table A1. Additional elastic constants (all in GPa) for the systems which are unstable, sheared or, in the case of the $\mathrm{Ni}_{3} \mathrm{Si}$ bulk, rotated into a coordination system in which the number of non-zero elastic constants is not minimum (unit cell vectors do not match the axes of the Cartesian coordination system).

\begin{tabular}{lcccccccccccc}
\hline $\mathrm{Ni}_{3} \mathrm{Si}$ States: & $C_{\mathbf{1 4}}$ & $C_{\mathbf{1 5}}$ & $C_{\mathbf{1 6}}$ & $C_{\mathbf{2 4}}$ & $C_{\mathbf{2 5}}$ & $C_{\mathbf{2 6}}$ & $C_{34}$ & $C_{35}$ & $C_{36}$ & $C_{45}$ & $C_{46}$ & $C_{56}$ \\
\hline bulk $\langle 1 \overline{2} 0\rangle\langle 001\rangle\langle 210\rangle$ & 0 & 26.5 & 0 & 0 & 0 & 0 & 0 & -26.5 & 1 & 0 & 0 & 0 \\
$\Sigma 5(210)^{\mathrm{Si}, \mathrm{Ni}}$ rectangular & 0 & -3 & 0 & 1 & 13 & -3 & 1 & 16 & 7 & -12 & -1 & -4 \\
$\Sigma 5(210)^{\mathrm{Si}, \mathrm{Ni}}$ sheared & 0 & -5 & 0 & -1 & 6 & 1 & 2 & -4 & 0 & 1 & 9 & -2 \\
\hline
\end{tabular}



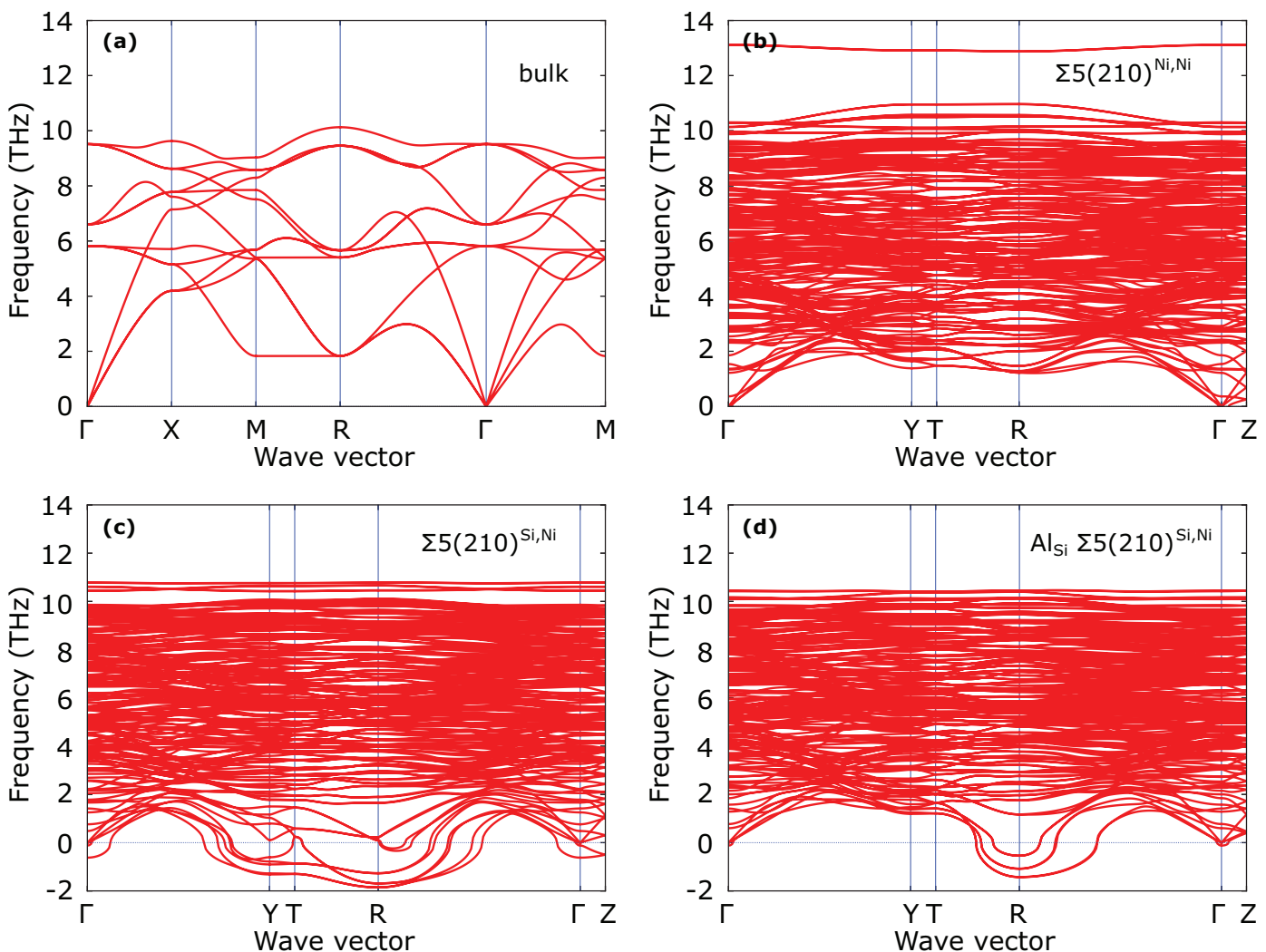

Figure A1. Phonon dispersion relations of (a) bulk $\mathrm{Ni}_{3} \mathrm{Si}$, (b) stable $\Sigma 5(210)^{\mathrm{Ni}, \mathrm{Ni}}$ grain boundary, (c) unstable $\Sigma 5(210)^{\mathrm{Si}, \mathrm{Ni}}$ grain boundary and (d) $\Sigma 5(210)^{\mathrm{Si}, \mathrm{Ni}}$ grain boundary partially stabilized by substitution of Si at the GB plane by Al.

\section{References}

1. Duscher, G.; Chisholm, M.F.; Alber, U.; Ruhle, M. Bismuth-induced embrittlement of copper grain boundaries. Nat. Mater. 2004, 3, 621-626. [CrossRef] [PubMed]

2. Lu, G.H.; Deng, S.H.; Wang, T.M.; Kohyama, M.; Yamamoto, R. Theoretical tensile strength of an Al grain boundary. Phys. Rev. B 2004, 69, 134106. [CrossRef]

3. Kohyama, M. Ab initio study of the tensile strength and fracture of coincidence tilt boundaries in cubic SiC: Polar interfaces of the $\{122\} \Sigma 9$ boundary. Phys. Rev. B 2002, 65, 184107. [CrossRef]

4. Ogata, S.; Umeno, Y.; Kohyama, M. First-principles approaches to intrinsic strength and deformation of materials: Perfect crystals, nano-structures, surfaces and interfaces. Model. Simul. Mater. Sci. Eng. 2009, 17, 013001. [CrossRef]

5. Pokluda, J.; Černý, M.; Šob, M.; Umeno, Y. Ab initio calculations of mechanical properties: Methods and applications. Prog. Mater. Sci. 2015, 73, 127-158. [CrossRef]

6. Tang, M.; Carter, W.C.; Cannon, R.M. Diffuse interface model for structural transitions of grain boundaries. Phys. Rev. B 2006, 73, 024102. [CrossRef]

7. Rohrer, G.S. Grain boundary energy anisotropy: A review. J. Mater. Sci. 2011, 46, 5881-5895. [CrossRef]

8. Cantwell, P.R.; Tang, M.; Dillon, S.J.; Luo, J.; Rohrer, G.S.; Harmer, M.P. Grain boundary complexions. Acta Mater. 2014, 62, 1-48. [CrossRef]

9. Rohrer, G.S. Measuring and Interpreting the Structure of Grain-Boundary Networks. J. Am. Ceram. Soc. 2011, 94, 633-646. [CrossRef]

10. Raabe, D.; Herbig, M.; Sandlöbes, S.; Li, Y.; Tytko, D.; Kuzmina, M.; Ponge, D.; Choi, P.P. Grain boundary segregation engineering in metallic alloys: A pathway to the design of interfaces. Curr. Opin. Sol. State Mater. Sci. 2014, 18, 253-261. [CrossRef]

11. Dillon, S.J.; Harmer, M.P.; Luo, J. Grain Boundary Complexions in Ceramics and Metals: An Overview. JOM 2009, 61, 38-44. [CrossRef] 
12. Shi, X.; Luo, J. Developing grain boundary diagrams as a materials science tool: A case study of nickel-doped molybdenum. Phys. Rev. B 2011, 84, 014105. [CrossRef]

13. Kundu, A.; Asl, K.M.; Luo, J.; Harmer, M.P. Identification of a bilayer grain boundary complexion in Bi-doped Cu. Scr. Mater. 2013, 68, 146-149. [CrossRef]

14. Bojarski, S.A.; Ma, S.; Lenthe, W.; Harmer, M.P.; Rohrer, G.S. Changes in the Grain Boundary Character and Energy Distributions Resulting from a Complexion Transition in Ca-Doped Yttria. Metall. Mater. Trans. A 2012, 43A, 3532-3538. [CrossRef]

15. Rickman, J.M.; Chan, H.M.; Harmer, M.P.; Luo, J. Grain-boundary layering transitions in a model bicrystal. Surf. Sci. 2013, 618, 88-93. [CrossRef]

16. Bojarski, S.A.; Harmer, M.P.; Rohrer, G.S. Influence of grain boundary energy on the nucleation of complexion transitions. Scr. Mater. 2014, 88,1-4. [CrossRef]

17. Frazier, W.E.; Rohrer, G.S.; Rollett, A.D. Abnormal grain growth in the Potts model incorporating grain boundary complexion transitions that increase the mobility of individual boundaries. Acta Mater. 2015, 96, 390-398. [CrossRef]

18. Zhou, N.; Luo, J. Developing grain boundary diagrams for multicomponent alloys. Acta Mater. 2015, 91, $202-216$. [CrossRef]

19. Moghadam, M.M.; Rickman, J.M.; Harmer, M.P.; Chan, H.M. The role of boundary variability in polycrystalline grain-boundary diffusion. J. Appl. Phys. 2015, 117, 045311. [CrossRef]

20. Lu, G.H.; Zhang, Y.; Deng, S.; Wang, T.; Kohyama, M.; Yamamoto, R.; Liu, F.; Horikawa, K.; Kanno, M. Origin of intergranular embrittlement of $\mathrm{Al}$ alloys induced by $\mathrm{Na}$ and Ca segregation: Grain boundary weakening. Phys. Rev. B 2006, 73, 224115. [CrossRef]

21. Yan, M.; Šob, M.; Luzzi, D.E.; Vitek, V.; Ackland, G.; Methfessel, M.; Rodriguez, C. Interatomic forces and atomic-structure of grain-boundaries in copper-bismuth alloys. Phys. Rev. B 1993, 47, 5571-5582. [CrossRef]

22. Braithwaite, J.S.; Rez, P. Grain boundary impurities in iron. Acta Mater. 2005, 53, 2715-2726. [CrossRef]

23. Christensen, M.; Wahnstrom, G. Co-phase penetration of $\mathrm{WC}(10 \overline{1} 0) / \mathrm{WC}(1 \overline{1} 0)$ grain boundaries from first principles. Phys. Rev. B 2003, 67, 115415. [CrossRef]

24. Du, Y.A.; Ismer, L.; Rogal, J.; Hickel, T.; Neugebauer, J.; Drautz, R. First-principles study on the interaction of $\mathrm{H}$ interstitials with grain boundaries in $\alpha$ - and $\gamma$-Fe. Phys. Rev. B 2011, 84, 144121. [CrossRef]

25. Asta, M.; Hoyt, J.J. Thermodynamic properties of coherent interfaces in f.c.c.-based Ag-Al alloys: A first-principles study. Acta Mater. 2000, 48, 1089-1096. [CrossRef]

26. Thomson, D.I.; Heine, V.; Payne, M.C.; Marzari, N.; Finnis, M.W. Insight into gallium behavior in aluminum grain boundaries from calculation on $\Sigma 11$ (113) boundary. Acta Mater. 2000, 48, 3623-3632. [CrossRef]

27. Wachowicz, E.; Ossowski, T.; Kiejna, A. Cohesive and magnetic properties of grain boundaries in bcc Fe with Cr additions. Phys. Rev. B 2010, 81, 094104. [CrossRef]

28. Wachowicz, E.; Kiejna, A. Effect of impurities on grain boundary cohesion in bcc iron. Comput. Mater. Sci. 2008, 43, 736-743. [CrossRef]

29. Sutton, A.P.; Balluffi, R.W. Interfaces in Crystalline Materials; Oxford University Press: Oxford, UK, 1995.

30. Lejček, P. Grain Boundary Segregation in Metals; Springer: Heidelberg, Germany, 2010.

31. Liu, C.T.; George, E.P.; Oliver, W.C. Grain-boundary fracture and boron effect in $\mathrm{Ni}_{3} \mathrm{Si}$ alloys. Intermetallics 1996, 4, 77-83. [CrossRef]

32. Vitek, V. Micromechanisms of intergranular brittle fracture in intermetallic compounds. J. Phys. III France 1991, 1, 1085-1097. [CrossRef]

33. Kruisman, J.J.; Vitek, V.; Hosson, J.D. Atomic structure of stoichiometric and non-stoichiometric grain boundaries in $\mathrm{A}_{3} \mathrm{~B}$ compounds with $\mathrm{L}_{2}$ structure. Acta Metall. 1988, 36, 2729-2741. [CrossRef]

34. Briant, C.L. Intermetallic Compounds: Principles; JohnWiley and Sons, Ltd.: New York, NY, USA, 1994; Volume 1, p. 895.

35. Stoloff, N.; Liu, C.; Deevi, S. Emerging applications of intermetallics. Intermetallics 2000, 8, $1313-1320$. [CrossRef]

36. Takasugi, T.; Izumi, O. Electronic and structural studies of grain boundary strength and fracture in $\mathrm{L}_{2}$ ordered alloys-I. On binary A 3 B alloys. Acta Metall. 1985, 33, 1247-1258. [CrossRef]

37. Taub, A.; Briant, C. Composition dependence of ductility in boron-doped, nickel-base $\mathrm{L}_{2}$ alloys. Acta Metall. 1987, 35, 1597-1603. [CrossRef]

38. Messmer, R.; Briant, C. The role of chemical bonding in grain boundary embrittlement. Acta Metall. 1982, 30, 457-467. [CrossRef] 
39. Liu, C.T.; White, C.L.; Horton, J. A. Effect of boron on grain-boundaries in Ni 3 Al. Acta Metall. 1985, 33, $213-229$. [CrossRef]

40. Schulson, E.; Briggs, L.; Baker, I. The strength and ductility of Ni ${ }_{3}$ Si. Acta Metall. Mater. 1990, 38, $207-213$. [CrossRef]

41. Aoki, K.; Izumi, O. Improvement in room temperature ductility of the $\mathrm{L}_{2}$ type intermetallic compound $\mathrm{Ni}_{3} \mathrm{Al}$ by boron addition. J. Jpn. Inst. Met. 1979, 43, 1190-1196. [CrossRef]

42. Takasugi, T.; Nagashima, M.; Izumi, O. Strengthening and ductilization of $\mathrm{Ni}_{3} \mathrm{Si}$ by the addition of $\mathrm{Ti}$ elements. Acta Metall. Mater. 1990, 38, 747-755. [CrossRef]

43. Heatherly, L.; George, E.; Liu, C.; Kumar, K. An Auger investigation of the grain-boundary chemistry in $\mathrm{Ni}_{3}(\mathrm{Si}, \mathrm{Ti})$ alloys. Mater. Sci. Eng. A 1998, 245, 80-87. [CrossRef]

44. Friák, M.; Všianská, M.; Holec, D.; Zelený, M.; Šob, M. Tensorial elastic properties and stability of interface states associated with $\Sigma 5$ (210) grain boundaries in $\mathrm{Ni}_{3}$ (Al, Si). Sci. Technol. Adv. Mater. 2017, 18, 273. [CrossRef] [PubMed]

45. Friák, M.; Všianská, M.; Holec, D.; Šob, M. Quantum-mechanical study of tensorial elastic and high-temperature thermodynamic properties of grain boundary states in superalloy-phase $\mathrm{Ni}_{3} \mathrm{Al}$. IOP Conf. Ser. Mater. Sci. Eng. 2017, 219, 012019. [CrossRef]

46. Slater, J.C. Introduction to Chemical Physics; McGraw-Hill: New York, NY, USA, 1939.

47. Lu, G.; Kioussis, N.; Wu, R.; Ciftan, M. First-principles studies of the $\Sigma 5$ tilt grain boundary in $\mathrm{Ni}_{3} \mathrm{Al}$. Phys. Rev. B 1999, 59, 891. [CrossRef]

48. Muller, D.A.; Singh, D.J.; Silcox, J. Connections between the electron-energy-loss spectra, the local electronic structure, and the physical properties of a material: A study of nickel aluminum alloys. Phys. Rev. B 1998, 57, 8181-8202. [CrossRef]

49. Mrovec, M.; Groeger, R.; Bailey, A.G.; Nguyen-Manh, D.; Elsässer, C.; Vitek, V. Bond-order potential for simulations of extended defects in tungsten. Phys. Rev. B 2007, 75, 104119. [CrossRef]

50. Lojkowski, W.; Fecht, H.J. The structure of intercrystalline interfaces. Prog. Mater. Sci. 2000, 45, 339-568. [CrossRef]

51. Kohyama, M. Computational studies of grain boundaries in covalent materials. Model. Simul. Mater. Sci. Eng. 2002, 10, R31-R59. [CrossRef]

52. Ochs, T.; Beck, O.; Elsässer, C.; Meyer, B. Symmetrical tilt grain boundaries in body-centred cubic transition metals: An ab initio local-density-functional study. Philos. Mag. A 2000, 80, 2405-2423. [CrossRef]

53. Všianská, M.; Šob, M. The effect of segregated sp-impurities on grain-boundary and surface structure, magnetism and embrittlement in nickel. Prog. Mat. Sci. 2011, 56, 817. [CrossRef]

54. Všianská, M.; Šob, M. Magnetically dead layers at sp-impurity-decorated grain boundaries and surfaces in nickel. Phys. Rev. B 2011, 84, 014418. [CrossRef]

55. Lejček, P.; Šob, M.; Paidar, V. Interfacial segregation and grain boundary embrittlement: An overview and critical assessment of experimental data and calculated results. Prog. Mater. Sci. 2017, 87, 83-139. [CrossRef]

56. Hohenberg, P.; Kohn, W. Inhomogeneous electron gas. Phys. Rev. 1964, 136, B864-B871. [CrossRef]

57. Kohn, W.; Sham, L.J. Self-consistent equations including exchange and correlation effects. Phys. Rev. 1965, 140, A1133-A1138. [CrossRef]

58. Kresse, G.; Hafner, J. Ab initio molecular dynamics for liquid metals. Phys. Rev. B 1993, 47, 558-561. [CrossRef]

59. Kresse, G.; Furthmüller, J. Efficient iterative schemes for ab initio total-energy calculations using a plane-wave basis set. Phys. Rev. B 1996, 54, 11169-11186. [CrossRef]

60. Kresse, G.; Joubert, D. From ultrasoft pseudopotentials to the projector augmented-wave method. Phys. Rev. B 1999, 59, 1758-1775. [CrossRef]

61. Perdew, J.P.; Burke, K.; Ernzerhof, M. Generalized Gradient Approximation Made Simple. Phys. Rev. Lett. 1996, 77, 3865-3868. [CrossRef] [PubMed]

62. Methfessel, M.; Paxton, A.T. High-precision sampling for Brillouin-zone integration in metals. Phys. Rev. $B$ 1989, 40, 3616-3621. [CrossRef]

63. Dronskowski, R.; Blöchl, P.E. Crystal Orbital Hamilton Populations (COHP). Energy-Resolved Visualization of Chemical Bonding in Solids based on Density-Functional Calculations. J. Phys. Chem. 1993, 97, 8617-8624. [CrossRef] 
64. Deringer, V.L.; Tchougreeff, A.L.; Dronskowski, R. Crystal Orbital Hamilton Population (COHP) Analysis as Projected from Plane-Wave Basis Sets. J. Phys. Chem. A 2011, 115, 5461-5466. [CrossRef] [PubMed]

65. Maintz, S.; Deringer, V.L.; Tchougreeff, A.L.; Dronskowski, R. Analytic Projection from Plane-Wave and PAW Wavefunctions and Application to Chemical-Bonding Analysis in Solids. J. Comput. Chem. 2013, 34, $2557-2567$. [CrossRef] [PubMed]

66. Maintz, S.; Deringer, V.L.; Tchougreeff, A.L.; Dronskowski, R. LOBSTER: A tool to extract chemical bonding from plane-wave based DFT. J. Comput. Chem. 2016, 37, 1030-1035. [CrossRef] [PubMed]

67. Yu, R.; Zhu, J.; Ye, H.Q. Calculations of single-crystal elastic constants made simple. Comput. Phys. Commun. 2010, 181, 671-675. [CrossRef]

68. Zhou, L.; Holec, D.; Mayrhofer, P.H. Ab initio study of the alloying effect of transition metals on structure, stability and ductility of CrN. J. Appl. Phys. 2013, 113, 043511. [CrossRef]

69. Togo, A.; Tanaka, I. First principles phonon calculations in materials science. Scr. Mater. 2015, 108, 1-5. [CrossRef]

70. Parlinski, K.; Li, Z.Q.; Kawazoe, Y. First-Principles Determination of the Soft Mode in Cubic $\mathrm{ZrO}_{2}$. Phys. Rev. Lett. 1997, 78, 4063-4066. [CrossRef]

71. Deringer, V.L.; Stoffel, R.P.; Wuttig, M.; Dronskowski, R. Vibrational properties and bonding nature of $\mathrm{Sb}_{2} \mathrm{Se}_{3}$ and their implications for chalcogenide materials. Chem. Sci. 2015, 6, 5255-5262. [CrossRef] [PubMed]

72. Zhou, G.; Bakker, H. Atomic disorder and phase transformation in $\mathrm{L}_{2}$-structure $\mathrm{Ni}_{3} \mathrm{Si}$ by ball milling. Acta Metall. Mater. 1994, 42, 3009-3017. [CrossRef]

73. Kumar, A.; Wang, J.; Tomé, C.N. First-principles study of energy and atomic solubility of twinning-associated boundaries in hexagonal metals. Acta Mater. 2015, 85, 144-154. [CrossRef]

74. Prikhodko, S.V.; Ma, Y.; Ardell, A.J.; Isaak, D.G.; Carnes, J.D.; Moser, S. Elastic constants of face-centered cubic and $\mathrm{L}_{2} \mathrm{Ni}-\mathrm{Si}$ alloys: Composition and temperature dependence. Metall. Mater. Trans. A 2003, 34, 1863-1868. [CrossRef]

75. Fu, C.L.; Ye, Y.Y.; Yoo, M.H. Theoretical investigation of the elastic constants and shear fault energies of $\mathrm{Ni}_{3} \mathrm{Si}$. Philos. Mag. Lett. 1993, 67, 179-185. [CrossRef]

76. Iotova, D.; Kioussis, N.; Lim, S.P. Electronic structure and elastic properties of the $\mathrm{Ni}_{3} \mathrm{X}(\mathrm{X}=\mathrm{Mn}, \mathrm{Al}, \mathrm{Ga}, \mathrm{Si}$, Ge) intermetallics. Phys. Rev. B 1996, 54, 14413-14422. [CrossRef]

77. Liu, L.; Chen, L.; Jiang, Y.; He, C.; Xu, G.; Wen, Y. Temperature Effects on the Elastic Constants, Stacking Fault Energy and Twinnability of $\mathrm{Ni}_{3} \mathrm{Si}$ and $\mathrm{Ni}_{3} \mathrm{Ge}$ : A First-Principles Study. Crystals 2018, 8, 364. [CrossRef]

78. Mouhat, F.; Coudert, F.X. Necessary and sufficient elastic stability conditions in various crystal systems. Phys. Rev. B 2014, 90, 224104. [CrossRef]

79. Černý, M. Elastic stability of magnetic crystals under isotropic compression and tension. Mater. Sci. Eng. A 2007, 462, 432-435. [CrossRef]

80. Titrian, H.; Aydin, U.; Friák, M.; Ma, D.; Raabe, D.; Neugebauer, J. Self-consistent Scale-bridging Approach to Compute the Elasticity of Multi-phase Polycrystalline Materials. MRS Proc. 2013, 1524, mrsf12-1524-rr06-03. [CrossRef]

81. Friák, M.; Counts, W.; Ma, D.; Sander, B.; Holec, D.; Raabe, D.; Neugebauer, J. Theory-Guided Materials Design of Multi-Phase Ti-Nb Alloys with Bone-Matching Elastic Properties. Materials 2012, 5, 1853-1872. [CrossRef]

82. Zhu, L.F.; Friák, M.; Lymperakis, L.; Titrian, H.; Aydin, U.; Janus, A.; Fabritius, H.O.; Ziegler, A.; Nikolov, S.; Hemzalová, P.; et al. Ab initio study of single-crystalline and polycrystalline elastic properties of Mg-substituted calcite crystals. J. Mech. Behav. Biomed. Mater. 2013, 20, 296-304. [CrossRef] [PubMed]

83. Gaillac, R.; Pullumbi, P.; Coudert, F.X. ELATE: An open-source online application for analysis and visualization of elastic tensors. J. Phys. Condens. Matter 2016, 28, 275201. [CrossRef] [PubMed]

84. Wolf, D.; Lutsko, J.F. Structurally induced supermodulus effect in superlattices. Phys. Rev. Lett. 1988, 60, 1170-1173. [CrossRef] [PubMed]

85. Kluge, M.D.; Wolf, D.; Lutsko, J.F.; Phillpot, S.R. Formalism for the calculation of local elastic constants at grain boundaries by means of atomistic simulation. J. Appl. Phys. 1990, 67, 2370-2379. [CrossRef]

86. Hughbanks, T.; Hoffmann, R. Chains of trans-edge-sharing molybdenum octahedra: Metal-metal bonding in extended systems. J. Am. Chem. Soc. 1983, 105, 3528-3537. [CrossRef]

87. Bylander, D.M.; Kleinman, L.; Mednick, K. Self-consistent energy bands and bonding of NiSi ${ }_{2}$. Phys. Rev. B 1982, 25, 1090-1095. [CrossRef] 
88. Yoo, M.; Fu, C.; Horton, J. Crack-tip dislocations and fracture behavior in $\mathrm{Ni}_{3} \mathrm{Al}$ and $\mathrm{Ni}_{3} \mathrm{Si}$. Mater. Sci. Eng. A 1994, 176, 431-437. [CrossRef]

89. Pang, X.Y.; Janisch, R.; Hartmaier, A. Interplanar potential for tension-shear coupling at grain boundaries derived from ab initio calculations. Model. Simul. Mater. Sci. Eng. 2016, 24, 015007. [CrossRef]

90. Razumovskiy, V.I.; Ruban, A.; Razumovskii, I.; Lozovoi, A.; Butrim, V.; Vekilov, Y. The effect of alloying elements on grain boundary and bulk cohesion in aluminum alloys: An ab initio study. Scr. Mater. 2011, 65, 926-929. [CrossRef]

91. Tahir, A.M.; Janisch, R.; Hartmaier, A. Hydrogen embrittlement of a carbon segregated $\Sigma$ 5(310)[001] symmetrical tilt grain boundary in $\alpha$-Fe. Mater. Sci. Eng. A 2014, 612, 462-467. [CrossRef]

92. Tahir, A.M.; Janisch, R.; Hartmaier, A. Ab initio calculation of traction separation laws for a grain boundary in molybdenum with segregated C impurites. Model. Simul. Mater. Sci. Eng. 2013, 21, 075005. [CrossRef]

93. Razumovskiy, V.I.; Vekilov, Y.K.; Razumovskii, I.M.; Ruban, A.V.; Butrim, V.N.; Mironenko, V.N. Effect of alloying elements and impurities on interface properties in aluminum alloys. Phys. Solid State 2011, 53, 2189-2193. [CrossRef]

94. Hristova, E.; Janisch, R.; Drautz, R.; Hartmaier, A. Solubility of carbon in $\alpha$-iron under volumetric strain and close to the $\Sigma 5(310)$ [001] grain boundary: Comparison of DFT and empirical potential methods. Comput. Mater. Sci. 2011, 50, 1088-1096. [CrossRef]

95. Janisch, R.; Ahmed, N.; Hartmaier, A. Ab initio tensile tests of Al bulk crystals and grain boundaries: Universality of mechanical behavior. Phys. Rev. B 2010, 81, 184108. [CrossRef]

96. Razumovskiy, V.I.; Lozovoi, A.Y; Razumovskii, I.M. First-principles-aided design of a new Ni-base superalloy: Influence of transition metal alloying elements on grain boundary and bulk cohesion. Acta Mater. 2015, 82, 369-377. [CrossRef]

97. Scheiber, D.; Razumovskiy, V.I.; Puschnig, P.; Pippan, R.; Romaner, L. Ab initio description of segregation and cohesion of grain boundaries in W-25at.\% Re alloys. Acta Mater. 2015, 88, 180-189. [CrossRef]

98. Janisch, R.; Elsässer, C. Interstitial impurities at grain boundaries in metals: Insight from atomistic calculations. Int. J. Mater. Res. 2009, 100, 1488-1493. [CrossRef]

99. Janisch, R.; Elsässer, C. Growth and mechanical properties of a MoC precipitate at a Mo grain boundary: An ab initio density functional theory study. Phys. Rev. B 2008, 77, 094118. [CrossRef]

100. Gemming, S.; Janisch, R.; Schreiber, M.; Spaldin, N.A. Density-functional investigation of the (113)[-110] twin grain boundary in Co-doped anatase $\mathrm{TiO}_{2}$ and its influence on magnetism in dilute magnetic semiconductors. Phys. Rev. B 2007, 76, 045204. [CrossRef]

101. Janisch, R.; Elsässer, C. Segregated light elements at grain boundaries in niobium and molybdenum. Phys. Rev. B 2003, 67, 224101. [CrossRef]

102. Šob, M.; Wang, L.G.; Vitek, V. Local stability of higher-energy phases in metallic materials and its relation to the structure of extended defects. Comput. Mater. Sci. 1997, 8, 100-106. [CrossRef]

103. Wang, L.G.; Šob, M.; Zhang, Z.Y. Instability of higher-energy phases in simple and transition metals. J. Phys. Chem. Solids 2003, 64, 863-872. [CrossRef]

104. Šob, M.; Wang, L.G.; Vitek, V. Ab initio calculation of the ideal tensile strength in copper and nickel aluminide. Kovove Mater. Met. Mater. 1998, 36, 145-152.

105. Šesták, P.;Friák, M.; Holec, D.; Všianská, M.; Šob, M. Strength and Brittleness of Interfaces in Fe-Al Superalloy Nanocomposites under Multiaxial Loading: An ab initio and Atomistic Study. Nanomaterials 2018, 8, 873. [CrossRef] [PubMed]

106. Černý, M.; Šesták, P.; Ǩehák, P.; Všianská, M.; Šob, M. Ab initio tensile tests of grain boundaries in the fcc crystals of $\mathrm{Ni}$ and Co with segregated sp-impurities. Mater. Sci. Eng. A 2016, 669, 218-225. [CrossRef]

107. Momma, K.; Izumi, F. VESTA 3 for three-dimensional visualization of crystal, volumetric and morphology data. J. Appl. Crystallogr. 2011, 44, 1272-1276. [CrossRef]

(C) 2018 by the authors. Licensee MDPI, Basel, Switzerland. This article is an open access article distributed under the terms and conditions of the Creative Commons Attribution (CC BY) license (http://creativecommons.org/licenses/by/4.0/). 